\title{
Understanding anthropomorphism in service provision: a meta-analysis of physical robots, chatbots, and other Al
}

\author{
Markus Blut $^{1}$ (D) Cheng Wang ${ }^{2} \cdot$ Nancy V. Wünderlich ${ }^{3} \cdot$ Christian Brock $^{4}$
}

Received: 6 June 2020 / Accepted: 1 December 2020 / Published online: 6 January 2021

(C) The Author(s) 2021

\begin{abstract}
An increasing number of firms introduce service robots, such as physical robots and virtual chatbots, to provide services to customers. While some firms use robots that resemble human beings by looking and acting humanlike to increase customers' use intention of this technology, others employ machinelike robots to avoid uncanny valley effects, assuming that very humanlike robots may induce feelings of eeriness. There is no consensus in the service literature regarding whether customers' anthropomorphism of robots facilitates or constrains their use intention. The present meta-analysis synthesizes data from 11,053 individuals interacting with service robots reported in 108 independent samples. The study synthesizes previous research to clarify this issue and enhance understanding of the construct. We develop a comprehensive model to investigate relationships between anthropomorphism and its antecedents and consequences. Customer traits and predispositions (e.g., computer anxiety), sociodemographics (e.g., gender), and robot design features (e.g., physical, nonphysical) are identified as triggers of anthropomorphism. Robot characteristics (e.g., intelligence) and functional characteristics (e.g., usefulness) are identified as important mediators, although relational characteristics (e.g., rapport) receive less support as mediators. The findings clarify contextual circumstances in which anthropomorphism impacts customer intention to use a robot. The moderator analysis indicates that the impact depends on robot type (i.e., robot gender) and service type (i.e., possession-processing service, mental stimulusprocessing service). Based on these findings, we develop a comprehensive agenda for future research on service robots in marketing.
\end{abstract}

Keywords Service robots $\cdot$ Anthropomorphism $\cdot$ Technology acceptance $\cdot$ Meta-analysis

Martin Mende served as Area Editor for this article.

Markus Blut

markus.blut@durham.ac.uk

Cheng Wang

cheng.wang@xjtlu.edu.cn

Nancy V. Wünderlich

nancy.wuenderlich@upb.de

Christian Brock

christian.brock@uni-rostock.de

1 Durham University Business School, Durham University, Mill Hill Lane Durham DH1 3LB UK

2 International Business School Suzhou, Xi'an Jiaotong-Liverpool University, 111 Ren Ai Road Suzhou 215123 Jiangsu China

3 Paderborn University, Warburger Str. 10033098 Paderborn Germany

4 University of Rostock, Ulmenstraße 6918057 Rostock Germany
Technology is vital for expansion of the service economy (Huang and Rust 2017). Service robots are expected to change the way services are provided and to alter how customers and firms interact (van Doorn et al. 2017). Service robots are defined as autonomous agents whose core purpose is to provide services to customers by performing physical and nonphysical tasks (Joerling et al. 2019). They can be physically embodied or virtual (for example, voice- or text-based chatbots). The market value for service robots is forecast to reach US\$ 699.18 million by 2023 (Knowledge Sourcing Intelligence 2018). SoftBank has sold more than 10,000 of its humanoid service robot, Pepper, since launching it in 2014 (Mende et al. 2019). Pepper is employed by service providers in restaurants, airports, and cruise liners to greet guests and help them navigate the location. It is highly likely that robots will become more common and that customers will have to use them more in the future.

The present study enhances understanding of how customers interact with and experience inanimate objects such 
as service robots. Marketing has long studied various customer-object relations. For example, studies have taken a sensual perception or affective relational perspective. As customers' initial responses to objects are often driven by the objects' sensual appeal, sensory marketing has explored how customers perceive objects through different inputs of their five senses (Bosmans 2006; Peck and Childers 2006). Additionally, scholars have explored emotional customerobject relations. These affective relations mainly occur in contexts regarding consumption objects and possessions, where product attachment and material possession love impact consumption behavior (Kleine and Baker 2004; Lastovicka and Sirianni 2011). Another literature stream examines how customers anthropomorphize objects, such as service robots, and assign human characteristics to them (Epley et al. 2007).

To facilitate customer-robot interactions, marketing managers often favor humanlike service robots to increase customers' perceptions of social presence (Niemelä et al. 2017). These robots have a human shape, show human characteristics, or imitate human behavior (Bartneck et al. 2009). In the virtual context, chatbots' mimicry of human behavior can often convince customers that they have been interacting with a human (Wünderlich and Paluch 2017). Novak and Hoffman (2019) note a growing consensus in marketing and psychology that anthropomorphism is important for understanding how customers experience inanimate objects (MacInnis and Folkes 2017; Waytz et al. 2014). Anthropomorphism in this study refers to the extent to which customers perceive service robots as humanlike, rather than to the extent to which firms design robots as humanlike. According to Epley et al. (2007, p. 865), this perception results from "the attribution of human characteristics or traits to nonhuman agents."

While marketing has found anthropomorphism to increase product and brand liking (Aggarwal and Gill 2012), whether anthropomorphism in service robots enhances customers' experiences is unclear. Some scholars argue that perception of humanlike qualities in service robots facilitates engagement with customers, since it "incorporates the underlying principles and expectations people use in social settings in order to fine-tune the social robot's interaction with humans" (Duffy 2003 , p. 181). However, others are more skeptical; as perceived anthropomorphism increases, "consumers will experience discomfort - specifically, feelings of eeriness and a threat to their human identity" (Mende et al. 2019, p. 539). Although scholars have frequently examined the impact of anthropomorphism on customer intention to use a service robot, results are inconsistent, showing positive (Stroessner and Benitez 2019), neutral (Goudey and Bonnin 2016), and negative (Broadbent et al. 2011) effects. Thus, clear management guidelines are lacking, which is unfortunate given firms' need to "carefully consider how to use AI [artificial intelligence] to engage customers in a more systematic and strategic way" (Huang and Rust 2020, p. 3).
In response to calls by Thomaz et al. (2020) and van Doorn et al. (2017) for more research on when and why customers anthropomorphize service robots and how anthropomorphism influences customer outcomes, the present study uses metaanalysis to enhance understanding of the role of anthropomorphism in influencing customer use intention of service robots. The meta-analysis develops and tests a comprehensive framework to clarify the effects of anthropomorphism on important customer outcomes, assess mediators, identify factors that affect customers' propensity to anthropomorphize robots, and analyze how contextual factors affect anthropomorphism (Grewal et al. 2018). We thus make several contributions.

First, we synthesize previous research on the relationship between robot anthropomorphism and customer use intention. While one literature stream refers to anthropomorphism theory and suggests that anthropomorphism has positive effects on technology use (Duffy 2003), other literature streams refer either to uncanny valley theory or expectation confirmation theory and argue in favor of negative effects (Ho and MacDorman 2010). Our meta-analysis resolves these inconsistent findings, clarifying whether and under what circumstances customers appreciate anthropomorphism, and whether this relates positively or negatively to technology perception and use intention. The results will guide managers in whether to consider anthropomorphism as a factor influencing robot use.

Second, we examine the mediating mechanisms between service robot anthropomorphism and customer use intention. Considering mediators is vital because it helps scholars avoid overestimating or underestimating the importance of anthropomorphism (Iyer et al. 2020). The literature is unclear about the importance of different mediators. One research stream considers relational mediators discussed in marketing (e.g., trust, satisfaction; Vlachos et al. 2016). A second stream, strongly influenced by information systems (IS) literature, uses the technology acceptance model (TAM) and considers mediators including perceived usefulness and ease of use (Canning et al. 2014). Other studies draw on concepts of human-robot interaction (HRI) and examine robot characteristics (e.g., intelligence and safety) as mediators (CastroGonzález et al. 2018). Yet other studies do not consider mediators at all (Wirtz et al. 2018). Our meta-analysis clarifies which theories are most likely to yield insights into mediating mechanisms.

Third, our meta-analysis examines the antecedents of anthropomorphism. Few service robot studies have examined which customer characteristics and/or robot design features impact the likelihood of anthropomorphizing a service robot. This is surprising, since van Doorn et al. (2017) emphasize the importance of understanding why customers anthropomorphize technology, and anthropomorphism theory argues that individuals differ in their likelihood of anthropomorphizing objects (Duffy 2003), and that an agent's humanlike features 
facilitate anthropomorphism (Castro-González et al. 2018). We therefore examine the impact of customer characteristics and robot design features on anthropomorphism, showing managers which customers are most receptive to anthropomorphism and how to design robots that trigger anthropomorphism perceptions.

Fourth, we examine the moderating influence of factors characterizing the study context. Blut et al. (2018) give initial indications that the service industry may impact the importance of several robot characteristics, including robot anthropomorphism. While previous research has examined some moderators, including the customer's cultural background and feelings of social power (Kim and McGill 2011), only a meta-analysis can provide a comprehensive assessment of contextual moderators. Our findings indicate that the effects of anthropomorphism are contingent on the robot and service types. Testing these moderators will enhance understanding of the generalizability of anthropomorphism effects.

We have identified several meta-analyses on robots in other research fields. Unlike the present study, these meta-analyses focus on health care and therapy contexts and examine the impact of service robots on patients' psychological and physiological well-being (Leng et al. 2019; Norouzi-Gheidari et al. 2012; Pu et al. 2019; Veerbeek et al. 2017). None of these studies measures anthropomorphism. However, Hancock et al.'s (2011) meta-analysis examines human-robot trust and the role of anthropomorphism. Our study differs from this research. Hancock et al. (2011) test various antecedents of human-robot trust, including anthropomorphism. The topic is related to our study, but the examined relationships are different. Our study focuses on the anthropomorphism construct instead and explores a more comprehensive nomological network around the anthropomorphism construct that is unique to our study. Our meta-analysis includes a larger and more recent body of primary research ${ }^{1}$ that allows the present meta-analysis to provide more up-to-date and generalizable insights on a more comprehensive number of relationships/ framework encompassing not only the antecedents of anthropomorphism, but also moderators, mediators, and outcomes.

\section{Meta-analytic framework and conceptual model}

The conceptual model of this meta-analysis is shown in Fig. 1. Anthropomorphism is the focal construct, and its impact on intention to use is the central relationship of interest. We

\footnotetext{
${ }^{1}$ Hancock et al.'s (2011) study is based on 21 independent samples and 116 effect sizes, whereas our meta-analysis includes a larger body of primary research of 108 samples and 3404 effect sizes; the additional studies are due to the different relationships examined and further number of years.
}

included three sets of variables to address three important issues. First, we examined antecedents of anthropomorphism to identify which customers are more likely to humanize service robots and which robot design features facilitate anthropomorphism. Second, we investigated mediators to reveal the mechanisms underlying how anthropomorphism influences intention to use. Finally, we analyzed moderators to identify when anthropomorphism impacts intention to use. Since findings on anthropomorphism are mixed for main effects, we present them as a summary meta-analysis and discuss how our results resolve past discrepancies. The moderator tests are novel and not tested by prior research; thus, we derive hypotheses for these effects. ${ }^{2}$

\section{Robot anthropomorphism and customer use intention}

Anthropomorphism is considered a basic psychological process of inductive inference that can facilitate social humannonhuman interactions. By making humans out of nonhumans, anthropomorphism can satisfy two basic human needs: the need for social connection and the need for control and understanding of the environment (Epley et al. 2008). Research has indicated that the innate human propensity to anthropomorphize objects is particularly salient for smart objects such as robots and AI, where anthropomorphizing is relatively easy (Novak and Hoffman 2019). People appear to anthropomorphize robots, especially service robots, more strongly than other forms of technology (Duffy 2003). Thus, anthropomorphism is a key construct for understanding people's responses to robots.

However, the relationship between robot anthropomorphism and customer use intention seems complex, and research results are mixed. On one hand, perceived humanlikeness can ease and facilitate human-robot interactions (Duffy 2003). During human-robot interaction, people can easily apply the social scripts and expectations of humanhuman interaction (Nass and Moon 2000). Thus, they tend to find the robot more controllable and predictable and the interaction easier and more familiar. Empirical studies have shown that perceived humanlikeness increases people's preference for, adoption of, and engagement with robots (Stroessner and Benitez 2019), and that anthropomorphism is especially effective when perceived humanlike features of the technology are similar to those of the customer (Al-Natour et al. 2011; Qiu and Benbasat 2009), thus supporting a positive effect of anthropomorphism on intention to use. However, this is not always the case. Goudey and Bonnin (2016) found that the

\footnotetext{
${ }^{2}$ We acknowledge that existing literature in related contexts suggests other potentially relevant antecedents of anthropomorphism as well as outcomes, mediators, and moderators that lack sufficient empirical support for inclusion in this meta-analysis. We discuss such variables in our future research section and in Table 6.
} 


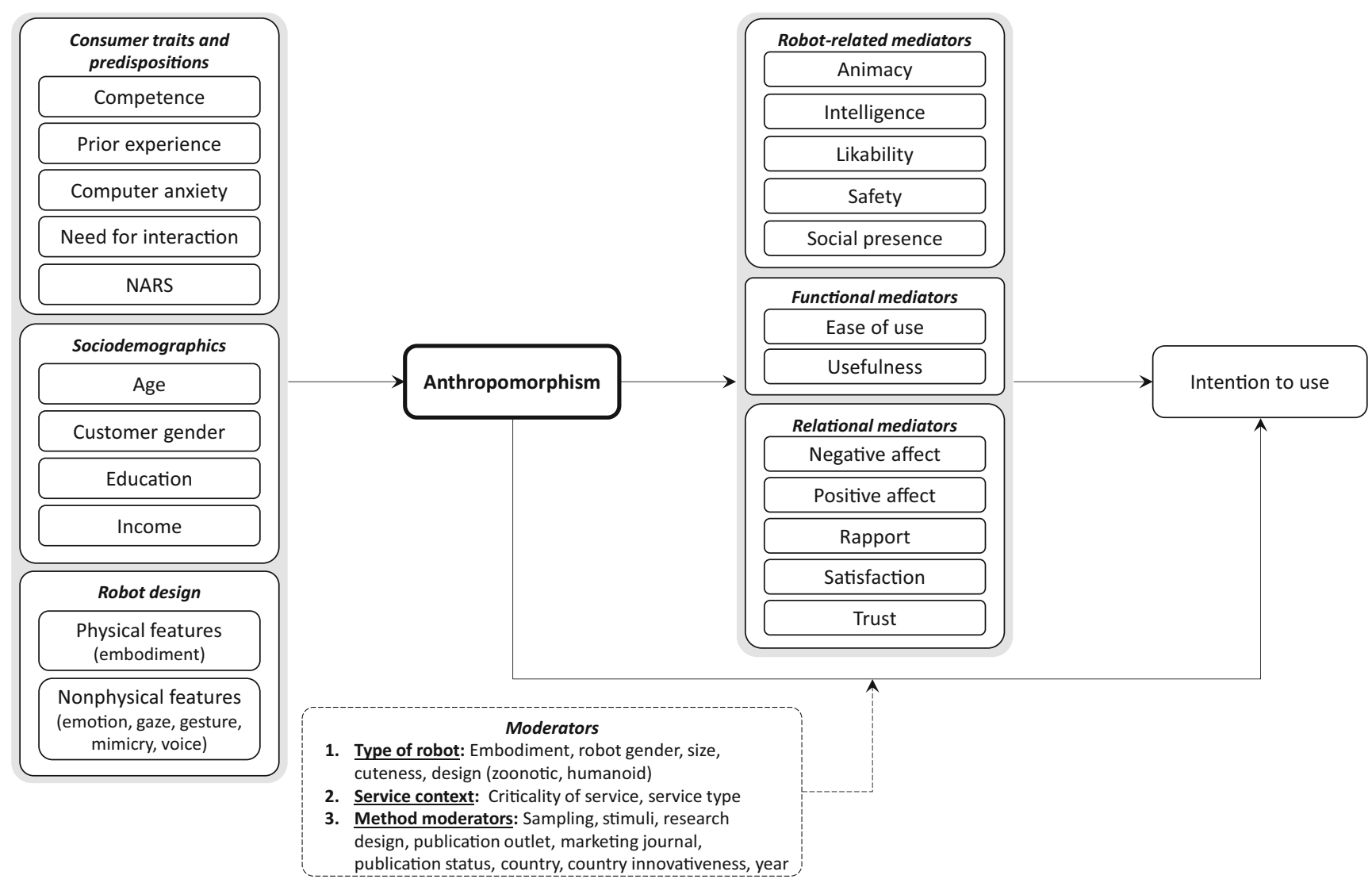

Fig. 1 Conceptual model for robot anthropomorphism. Note: $N A R S=$ negative attitudes toward robots in daily life

anthropomorphism of a companion robot did not increase use intention thereof, and some studies have found that people prefer a less humanlike robot (Broadbent et al. 2011) or an explicitly machinelike robot (Vlachos et al. 2016), suggesting a negative effect of anthropomorphism. This seems to support Mori's (1970) uncanny valley hypothesis that the use intention of a robot does not always increase with its humanlikeness; people may find a highly humanlike robot creepy and uncanny, and feelings of eeriness or discomfort may lead to rejection. In addition, Goetz et al. (2003) found that although people prefer humanlike robots for social roles, they prefer machinelike robots for more investigative roles, such as lab assistant. These mixed findings indicate the complexity of the relationship between anthropomorphism and use intention, and suggest that the effects of robot anthropomorphism on customer use intention are multi-faceted and contingent. To address this complexity and offer a fuller understanding of this important relationship, we included relevant mediators and moderators in our meta-analysis.

\section{Antecedents of anthropomorphism}

We considered two sets of antecedents: customer characteristics and robot design features, since anthropomorphism is not merely the result of a process triggered by an agent's humanlike features but also reflects customer differences in anthropomorphizing tendencies (Waytz et al. 2014). To select relevant customer characteristics as antecedent variables, we focused on five customer traits and predispositions that have been shown to impact customer use of new technologies: competence, prior experience, computer anxiety, need for interaction, and negative attitudes toward robots (NARS), all of which are technology-related psychological factors. The first four variables come from Epley et al.'s (2007) theory of anthropomorphism, and the last variable is a robot-related general attitude frequently used in HRI research. We also included sociodemographic variables as antecedents. Finally, we included major physical and nonphysical robot design features as antecedents of anthropomorphism.

\section{Traits and predispositions}

Competence Competence can be defined as the customer's potential to use a service robot to complete a task or performance successfully. It is a multi-faceted construct composed of an individual's knowledge of and ability to use a robot. It relates to individual factors such as knowledge, expertise, and self-efficacy (Munro et al. 1997). According to Epley et al. (2007), the first of the three psychological determinants of anthropomorphism is elicited agent knowledge; for customers 
who are knowledgeable about robots, anthropomorphic knowledge and representation are readily accessible and applicable, and therefore they are more likely to humanize the robot. The literature provides limited empirical evidence for a positive effect of competence on anthropomorphism, suggesting that after interacting with or using a robot, people tend to anthropomorphize it more (Fussell et al. 2008). Other studies, however, have found no influence (Ruijten and Cuijpers 2017) or even a negative relationship (Haring et al. 2015). It seems that the more people are capable of using a robot, the lower their anthropomorphic tendency, because there is no need to facilitate the interaction by humanizing the robot.

Prior experience Prior experience comprises the individual's opportunity to use a specific technology (Venkatesh et al. 2012). In contrast to competence, robot-related experience implies previous initial contact or interaction with a service robot that does not necessarily include fulfilling a task (MacDorman et al. 2009). The influence of robot-related experience on anthropomorphism is unclear, with contradictory findings. Some studies provide evidence of a positive effect on anthropomorphism (Aroyo et al. 2017), in line with Epley et al. (2007). The elicited agent knowledge in the form of robot-related experience could result in the projection of human attributes to the service robot (Epley et al. 2007). However, several studies indicate a negative effect of experience on anthropomorphism (Haring et al. 2016), or a nonsignificant effect (Stafford 2014).

Computer anxiety Computer anxiety is the degree of an individual's apprehension, or even fear, regarding using computers (Venkatesh 2000). Robots are essentially a computer-based technology, and people with different anxiety levels may react differently to robots. According to Epley et al. (2007), the second determinant of anthropomorphism is effectance, the motivation to explain and understand nonhuman agents' behavior. People high in computer anxiety are more likely to feel a lack of control and uncertain about interacting with a robot, and so their effectance motivation is typically stronger; that is, they have a higher desire to reduce uncertainty by controlling the robot. Anthropomorphism can satisfy this need by increasing someone's ability to make sense of a robot's behavior and their confidence in controlling the robot during the interaction (Epley et al. 2008). Thus, anxiety associated with uncertainty should increase the tendency to humanize a robot.

Need for interaction Like the need to belong and the need for affiliation, the need for interaction is a desire to retain personal contact with others (particularly frontline service employees) during a service encounter (Dabholkar 1996). This relates to the third psychological determinant of anthropomorphism, sociality, which is the need and desire to establish social connections with other humans (Epley et al. 2007). Research indicates that lonely people have a stronger tendency to humanize robots, perhaps because of social isolation, exclusion, or disconnection (Kim et al. 2013). Anthropomorphism can satisfy their need to belong and desire for affiliation by enabling a perceived humanlike connection with robots. Similarly, in a robot service context where social connection with frontline service employees is lacking, customers with a greater need for interaction may compensate and attempt to alleviate this social pain by perceiving a service robot as more humanlike, thus creating a humanlike social interaction (Epley et al. 2008). Therefore, need for interaction should increase customers' tendency to humanize a service robot.

Negative attitudes toward robots in daily life (NARS) The concept of NARS (Nomura et al. 2006) captures a general attitude and predisposition toward robots, and is a key psychological factor preventing humans from interacting with robots. While both anthropomorphism and NARS are important constructs in HRI research, their relationship remains understudied and unclear (Destephe et al. 2015). We suggest that NARS may influence anthropomorphism in a similar way to computer anxiety, because both are negative predispositions toward technology (Broadbent et al. 2009). A distinction is important, as computer anxiety is broader (referring to computer technology in general) and emotional (involving fear), whereas NARS is more specific (robot-focused) and attitudinal (involving dislike); nevertheless, the former may lead to the latter (Nomura et al. 2006). Customers with high NARS will feel uncomfortable when interacting with a robot in a service encounter because in general they do not like robots. Hence, in order to facilitate the interaction and improve the service experience, they will tend to anthropomorphize the robot and treat it like a human service employee. We predict a positive influence of NARS on anthropomorphism.

\section{Sociodemographics}

Age In general, age is found to negatively impact people's willingness to use robots (Broadbent et al. 2009); older people are more skeptical about technology, have more negative attitudes toward robots, and therefore have lower intention to use them. However, a study on healthcare robots found no age effects, suggesting that age need not be a barrier (Kuo et al. 2009). Regarding age influences on anthropomorphism, the literature has focused on children and elderly people, and findings suggest that these segments have a strong tendency to humanize robots (Sharkey and Sharkey 2011). For example, there is evidence that children anthropomorphize nonhuman agents more than adults do (Epley et al. 2007); they tend to ascribe human attributes such as free will, preferences, and emotions even to simple robots, although this tendency decreases with age. There are also indications that people are more likely to anthropomorphize robots as their age increases (Kamide et al. 2013). 
Customer gender Research shows that in general men hold more favorable attitudes toward robotic technologies, tend to perceive robots as more useful, and are more willing to use robots in their daily lives; women are more skeptical about interacting with robots, tend to evaluate them more negatively, and are less likely to use them (de Graaf and Allouch 2013). Therefore, most studies have found that women anthropomorphize robots more strongly than men do (Kamide et al. 2013), perhaps because of high effectance and sociality motivations resulting from technology anxiety or a need for social connection (Epley et al. 2007). Nevertheless, some studies have argued that men tend to perceive a robot as an autonomous person and therefore anthropomorphize robots more compared to women (de Graaf and Allouch 2013). Others have found no gender differences (Athanasiou et al. 2017).

Education There is a lack of clarity about the effects of an individual's educational level on their perceptions and evaluations of robots (Broadbent et al. 2009). Evidence that higher education is associated with more positive attitudes toward robots is limited (Gnambs and Appel 2019). Research has yet to examine explicitly whether and how anthropomorphic tendencies vary with educational level. However, anthropomorphism theory suggests that people of modern cultures are more familiar with and knowledgeable about technological devices than those of nonindustrialized cultures (Epley et al. 2007). Since they have greater understanding of how these technological devices work and how to use them, they are less likely to anthropomorphize them. This argument suggests a negative effect of education on anthropomorphism, because people of modern cultures are generally better educated than those of nonindustrialized cultures.

Income Income is the least examined sociodemographic factor in HRI research. Gnambs and Appel (2019) found that whitecollar workers held slightly more favorable attitudes toward robots than blue-collar workers. While there is no direct empirical evidence for the effect of income on anthropomorphism, we suggest that it may be similar to the effect of education, because education and income are highly related and are both indicators of social class. People with higher incomes have more opportunities to interact with innovative technologies such as service robots at work and in their daily lives. They are more capable of using robots, and therefore more likely to acquire nonanthropomorphic representations of robots' inner workings and less likely to humanize them (Epley et al. 2007).

\section{Robot design}

Physical features It is relatively intuitive that a robot's physical appearance or embodiment can affect the extent to which it is anthropomorphized. Research has consistently shown that the presence of human features such as head, face, and body increases the perceived humanlikeness of a robot (Erebak and Turgut 2019; Zhang et al. 2010). These physical features serve as observable cues of humanlikeness; hence, the more human features a robot possesses, the more strongly it is anthropomorphized.

Nonphysical features Nonphysical features mainly refer to robots' behavioral characteristics, such as gaze, gesture, voice, and mimicry. Research shows that robots with the abilities to make eye contact, use gestures, move, and talk when interacting with people are perceived as more humanlike than those without such abilities, and that the more a robot gazes, gestures, moves, and talks like a human, the more anthropomorphic it is perceived (Kompatsiari et al. 2019; Salem et al. 2013; Zhang et al. 2010). However, this positive effect of behavioral features on anthropomorphism is sometimes found nonsignificant (Ham et al. 2015; Kim et al. 2019). Nonphysical features also include a robot's emotionality and personality, which also influence people's anthropomorphic perceptions. For example, Novikova (2016) reported that an emotionally expressive robot was rated significantly higher on anthropomorphism versus a nonemotional robot. Moshkina (2011) found that an extraverted robot was rated as more humanlike than an introverted one.

\section{Mediators of anthropomorphism}

To provide a full account of the multi-faceted effects of robot anthropomorphism on customer use intention, we examined three sets of mediators from the literature. First, from HRI research we drew four major robot characteristics as robotrelated mediators (Bartneck et al. 2009); to capture the social aspect of a service robot, we also included social presence as a fifth robot characteristic (van Doorn et al. 2017). Second, from technology acceptance research we included usefulness and ease of use as functional mediators (Davis et al. 1989). Robots are essentially a form of technology, and these two variables appear to play key mediating roles in technology acceptance (Blut et al. 2016; Blut and Wang 2020). Third, drawing on the relationship marketing literature, we incorporated five common relational mediators; unlike other forms of technology, relationship-building with robots, especially service robots, is possible and even desired by customers. Thus, we extended Wirtz et al.'s (2018) robot acceptance model by systematically examining robot-related, functional, and relational factors as mediators in the anthropomorphism-use intention relationship. We now discuss the effect of anthropomorphism on each mediator. We will not discuss the effects of mediators on use intention, because they are wellestablished in the relevant literature on HRI, technology acceptance, and marketing. 


\section{Robot-related mediators}

Animacy Animacy is the extent to which a robot is perceived as being alive (Bartneck et al. 2009). Robots high in animacy are lifelike creatures that seem capable of connecting emotionally with customers and triggering emotions. Research often reports a highly positive correlation between anthropomorphism and animacy, suggesting conceptual overlap (Ho and MacDorman 2010) as being alive is an essential part of being humanlike (Bartneck et al. 2009). For example, CastroGonzález et al. (2018) found that the more humanlike a robot's mouth is perceived by people, the more alive the robot is rated. Thus, anthropomorphism should positively impact animacy; the more a robot is humanized, the more lifelike the perception. In service contexts, this means that when customers perceive a service robot as more humanlike, they are more likely to feel as if they are interacting with a human service employee rather than a machine.

Intelligence Intelligence is the extent to which a robot appears to be able to learn, reason, and solve problems (Bartneck et al. 2009). There is evidence that anthropomorphism increases customers' perceptions of the intelligence of various smart technologies, including robots. Canning et al. (2014) showed that customers perceived humanlike robots as more intelligent than machinelike ones. When people anthropomorphize a robot, they typically treat it as a human being and expect it to exhibit aspects of human intelligence (Huang and Rust 2018). The more humanlike the robot is perceived, the more human intelligence people tend to ascribe to it. In service contexts, this suggests that when customers humanize a service robot, they tend to have higher expectations of its ability to deliver a service.

Likability Likability is the extent to which a robot gives positive first impressions (Bartneck et al. 2009). Attractiveness is a similar concept, and anthropomorphism can help to make a robot aesthetically appealing and socially attractive. Numerous studies have confirmed a positive effect of anthropomorphism on likeability (Castro-González et al. 2018; Stroessner and Benitez 2019). When people humanize a robot, it becomes more similar to them, which leads to a good first impression (van Doorn et al. 2017). Therefore, the greater the tendency to anthropomorphize a robot, the more people like the robot. In a service context, the positive effect of anthropomorphism on likability means that the humanlikeness of a service robot will enhance first impressions of the robot as a service provider. However, in line with uncanny valley theory (Mori 1970), some studies have found that a robot's likability does not always increase with anthropomorphism; if it feels uncannily human, people find it unlikable (Mende et al. 2019).

Safety Safety is the customer's perception of the level of danger involved in interacting with a robot (Bartneck et al., 2009).
It relates to feelings of risk and invasion of privacy. Bartneck et al. (2009) suggested that for someone to use a robot as a partner and coworker, it is necessary to achieve a positive perception of safety. This is especially true for service robots, because customer-robot interaction and co-production are inevitable. According to Epley et al. (2007), anthropomorphism can facilitate perceptions of safety by increasing the sense of the predictability and controllability of the nonhuman agent during interactions, thereby reducing feelings of risk and danger. For example, Benlian et al. (2019) showed that feelings of privacy invasion when using smart home assistants are lower when the technology is anthropomorphized by users. Thus, the literature supports a positive effect of anthropomorphism on perceived safety. In a service context, this suggests that the more a customer perceives a service robot as humanlike, the safer the service experience appears.

Social presence Social presence is the extent to which a human believes that someone is really present (Heerink et al. 2008). In HRI, social presence is "the extent to which machines (e.g., robots) make consumers feel that they are in the company of another social entity" (van Doorn et al. 2017, p. 44). This robot characteristic can satisfy sociality needs (Epley et al. 2007) and is therefore important for those with a greater need for interaction. The relationship between anthropomorphism and social presence is intuitive and straightforward. By making humans out of robots, people feel that they are interacting with and connecting to another person. Therefore, anthropomorphism evokes a sense of social presence, and literature widely supports this positive effect (Kim et al. 2013). Thus, in a service context, robots that are perceived as more humanlike can provide customers with a stronger social presence, thereby enriching social interaction.

\section{Functional mediators}

Ease of use As a key determinant in the technology acceptance model (TAM), ease of use is the degree to which a customer finds using a technology to be effortless (Davis et al. 1989). With few exceptions (Wirtz et al. 2018), ease of use has not been examined in robot studies. However, research suggests that anthropomorphism makes a robot more humanlike and thus more familiar. Familiarity can help people learn how to use a robot and interact with it more easily, and humanlikeness makes this interaction more natural (Erebak and Turgut 2019); this will increase the perceived ease of use. Hence, a positive effect of anthropomorphism on ease of use is expected. In a service context, this means that customers tend to see a humanlike service robot as easier to work with than a machinelike one. However, empirical analysis is lacking, barring one study that did not support this effect (Goudey and Bonnin 2016). 
Usefulness Defined as the subjective probability that using a technology will improve the way a customer completes a given task (Davis et al. 1989), usefulness is another key determinant in TAM. Epley et al. (2007) suggested that anthropomorphism increases the perceived usefulness of robots in two ways. First, facilitating anthropomorphism can encourage a sense of efficacy that improves interaction with a robot. Second, anthropomorphism can increase the sense of being socially connected to the robot and thus its perceived usefulness. The literature generally supports a positive effect of anthropomorphism on usefulness. Canning et al. (2014) found that people rated humanlike robots higher than mechanical ones on utility, and Stroessner and Benitez (2019) found that humanlike robots were perceived as more competent than machinelike ones. However, Goudey and Bonnin (2016) found this effect to be nonsignificant. In a service context, the positive effect of anthropomorphism on usefulness suggests that customers will have more confidence in the ability of more humanlike robots to provide better services.

\section{Relational mediators}

Negative affect Defined as intense negative feelings directed at someone or something (Fishbach and Labroo 2007), feelings of negative affect a robot may elicit include discomfort such as eeriness, strain, and threat. According to Mori's (1970) uncanny valley hypothesis, highly humanlike robots generate feelings of eeriness, and people find such robots creepy because uncanny humanlikeness threatens people's human identity. Therefore, when interacting with highly humanlike robots, people may experience heightened arousal and negative emotions (Broadbent et al. 2011). Research shows that people perceive humanlike robots with greater unease than machinelike robots, and that children may fear highly humanlike robots (Kätsyri et al. 2015). In a service context, Mende et al. (2019) found that customers experienced feelings of eeriness and threat to human identity when interacting with a humanoid service robot and responded more negatively to a robot that was perceived as more humanlike. Therefore, anthropomorphism may not always be desirable, and to avoid causing negative emotions a robot should not be perceived as too humanlike.

Positive affect Defined as intense positive feelings directed at someone or something (Fishbach and Labroo 2007), feelings of positive affect a robot may elicit include enjoyment, pleasure, and warmth. Marketing research indicates that anthropomorphized products and brands evoke positive emotional responses. Customers view such products and brands as more sociable and are more likely to connect to them emotionally and experience feelings of warmth (van Doorn et al. 2017). Regarding robots, van Pinxteren et al. (2019) found that a robot's humanlikeness positively influenced customers' perceived enjoyment. Kim et al. (2019) reported a positive effect of anthropomorphism on pleasure and warmth, suggesting that anthropomorphism enables a humanlike emotional connection with a nonhuman agent. It seems that anthropomorphism can elicit both positive and negative emotions toward a robot, with opposite effects on customer use intention, making this relationship complex.

Rapport Rapport in this context is the personal connection between a customer and a robot (Wirtz et al. 2018). Building rapport with machines and technologies is often impossible or unnecessary; with service robots, however, it is both possible and desirable (Bolton et al. 2018). This is especially true in services, where rapport (with an employee or robot) is an important dimension in customer experience. Through anthropomorphism, people tend to perceive a robot to be more lifelike and sociable and feel a stronger sense of social connectedness, making emotional attachment to and bonding with the robot more likely. Thus, anthropomorphism facilitates human-robot rapport, making it easier, more desirable, and more meaningful. In a service context, Qiu et al. (2020) found that when customers humanize a service robot, they are more likely to build rapport with it.

Satisfaction Satisfaction is defined as an affective state resulting from a customer evaluation of a service provided by a company (Westbrook 1987). With few exceptions, satisfaction has not been examined in HRI research. However, given the central role of satisfaction in marketing and its established influence on customers' behavioral intentions, we include it as a mediator between anthropomorphism and customer intention to use a robot. Our discussion shows that anthropomorphism can improve people's perceptions (e.g., perceived intelligence), evaluations (e.g., usefulness), and relationships (e.g., rapport) with a robot. Hence, we predict a positive effect of anthropomorphism on satisfaction. However, research also suggests that when a robot is perceived as more humanlike, people tend to treat it as a real person and expect it to show human intelligence. Their expectations regarding the robot's human capabilities are increased, and they are likely to experience disappointment when the robot fails to meet those expectations (Duffy 2003).

Trust In a service context, trust is a psychological expectation that others will keep their promises and will not behave opportunistically in expectation of a promised service (Ooi and Tan 2016). Anthropomorphism of service robots may help establishing and increasing trust. When people attribute human capabilities to a nonhuman agent, they tend to believe that the agent is able to perform the intended functions competently. In our context, this means that customers put more trust in the ability of a more humanlike 
robot to deliver a service. This positive effect of anthropomorphism on trust receives general support in the literature. Waytz et al. (2014) found that people trusted an autonomous vehicle more when it was anthropomorphized, de Visser et al. (2016) showed that a robot's humanlikeness is associated with greater trust resilience, and van Pinxteren et al. (2019) confirmed that anthropomorphism of a humanoid service robot drove perceived trust in the robot. However, Erebak and Turgut (2019) found no effect of anthropomorphism on trust. Hancock et al.'s (2011) meta-analysis examined the impact of anthropomorphism on trust together with other robot attributes; the reported effect size is rather weak and nonsignificant.

\section{Moderators of the anthropomorphism-use intention relationship}

Several studies have examined moderators of the relationship between anthropomorphism and use intention. These studies have considered customer characteristics (the individual's cultural background and feelings of social power), robot appearance and task, and situational factors (Fan et al. 2016; Kim and McGill 2011; Li et al. 2010). However, most have focused on one study context and only a few types of service robots. The present meta-analysis systematically analyzes two sets of variables that may exert a moderating influence: robot types and service contexts.

First, we focus on robot types that have a large impact on the robot's overall appearance and behavior, as shown in Table 1. Anthropomorphism represents an important driver for customer decision-making and use intention. However, the importance of anthropomorphism may vary for different robot types since robots may display characteristics and behaviors that amplify or buffer the effect of anthropomorphism. Research in HRI has shown that robot behavior is strongly shaped by design features, in particular by physical embeddedness and morphology (Pfeifer et al. 2007). In addition, the design decision to assign features of more or less obvious gender orientation to a robot can bias perceptions of the robot because of gender-stereotyping (Carpenter et al. 2009). Another powerful design strategy pertains to the level of cuteness or the choice of a zoonotic body form for the robot. Both characteristics can endear the robot to the customer and produce a strong affective bond.

Second, drawing on task-technology fit (TTF) theory we propose that service contexts moderate the relationship between anthropomorphism and intention to use the robot (Table 1; Goodhue and Thompson 1995). TTF suggests that technology has to meet the customer's requirements when engaging in specific tasks, such as receiving services from a robot. If the technology meets the customer's needs during service provision (e.g., service robot anthropomorphism), the experience will be more satisfying and the customer more likely to use the technology again (Goetz et al. 2003). We examine five moderators characterizing the service context. We also control for the influence of various method moderators, as shown in Table 1.

\section{Method}

\section{Search strategy, inclusion criteria, and data collection}

We used several keywords to identify empirical papers for inclusion in the meta-analysis: anthropomorphism, humanness, humanlike, human-like, humanlikeness, and human-likeness in combination with service robots, social robots, and robots. We searched for these terms in electronic databases such as ABI/INFORM, Proquest, and EBSCO (Business Source Premier). Further, we searched in Google Scholar and dissertation databases to identify studies published in grey literature such as conference proceedings and dissertations. Next, we identified which papers cited key studies in the field that develop measures for anthropomorphism (i.e., Bartneck et al. 2009; Ho and MacDorman 2010) and which proposed conceptual frameworks including robot anthropomorphism as a key variable (i.e., van Doorn et al. 2017; Wirtz et al. 2018). We also contacted authors in the field to request access to unpublished studies. In the meta-analysis, we included studies (1) that examine the relationship between anthropomorphism of service robots with at least one other relevant variable from our metaanalytic framework, (2) that are quantitative rather than qualitative or conceptual, and (3) that report statistical information that can be used as or converted to an effect size. Studies not meeting these criteria were excluded. In total, we collected 3404 usable effect sizes reported by 11,053 customers. This information was extracted from 108 independent samples in 71 studies (Web Appendix A). The meta-analysis includes eight independent samples from three unpublished studies; one dataset was unpublished at the point of analysis and has since been published.

\section{Effect size integration and multivariate analyses}

The coded variables and their definitions are displayed in Web Appendix B. We integrated effect sizes (i.e., correlations) using Hunter and Schmidt's (2004) randomeffects meta-analytic approach. Accordingly, we first corrected the effect sizes for measurement error in the dependent and independent variables. We divided the correlations by the square root of the product of the reliabilities of the two constructs involved. Next, we weighted the measurement error-corrected correlations by the 
Table 1 Influence of moderators on the anthropomorphism-intention to use relationship

Moderator Theoretical explanation for expected relationship with estimates

Prediction

Robot type-related moderators

Physical embodiment (H1a)

Robot gender (H1b)

Size $(\mathrm{H} 1 \mathrm{c})$

Cuteness (H1d)

Zoonotic design (H1e)
Robots can have virtual representations only (e.g., chatbots being assigned to an avatar) or physical bodies (e.g., Pepper). Research comparing human reactions to physical (vs. nonphysical) robots has identified a strong preference for embodied robots across contexts (Wainer et al. 2006). Physical embodiment increases robots' appeal and social presence, and customers perceive physical robots as possessing more positive personality traits (perceptiveness, watchfulness, helpfulness, and enjoyableness) compared to virtual agents such as chatbots and avatars (Wainer et al. 2006). Consequently, customers empathize more with physically embodied robots than with virtual robots. We argue that physical robots convey perceptions of social presence in the service encounter. Thus, as per social presence theory (Wirtz et al. 2018), physical robots are more appealing for customers, and the degree of anthropomorphism of physical robots is less important for intention to use than the degree of anthropomorphism of robots with no physical representation

Robots are machines without organic gender or sexuality; however, robot designers can add gender cues to robots' appearance, voice, or name (Nomura 2017). Customers may use these gender cues to make gender-stereotypical inferences (Eyssel and Hegel 2012). Stereotypes assigned to robot gender resemble those assigned to human gender; whereas people ascribe traits related to interpersonal warmth to females, they perceive males predominantly in terms of agentic features such as assertive, dominant, and authoritative behavior (Spence et al. 1974). In line with these stereotypes, customers perceive female robots as more affable, polite, and affectionate than their male counterparts (Eyssel and Hegel 2012). We argue that these stereotypes apply in service contexts, with male robots perceived as more suitable because they are typically associated with more agentic or businesslike features. Likewise, we argue that the stereotypes hold true for female robots, which are perceived as less suitable in a service context and are less likely to be accepted. As anthropomorphism is a strong driver for robot acceptance (Stroessner and Benitez 2019), it can balance out the stereotype effect of female robot gender on the customer's intention to use. Thus, anthropomorphism will be a more important predictor for female robots than for nonfemale robots (e.g., male robots or robots with no or inconclusive gender cues)

Robots vary greatly in size; Pepper is $120 \mathrm{~cm}$, Aibo is $20 \mathrm{~cm}$, and Nao is $58 \mathrm{~cm}$ Large service robots > small service robots tall. For performing physical tasks, a robot's size is crucial, and many robots need to apply considerable force in order to perform their operations.

Customers may perceive interactions with physically superior robots as risky. Rae et al. (2013) found that if a robot was much shorter than a human, the human tended to feel more in control of the conversation. Because people perceive moderately anthropomorphic robots as less threatening (Ferrari et al. 2016), we argue that the perception of a robot as being humanlike will counterbalance the threatening effect of large robots. Thus, anthropomorphism as a driver for robot use is more important for larger robots

An object's cuteness entails it being seen as endearingly attractive (Nenkov and Scott 2014). The baby schema comprises large eyes and forehead, and small nose and jaw - features that are associated with neoteny and universally considered endearing. They elicit responses from adults that increase attention to and protection of helpless infants, stimulating caretaking behavior and social engagement (Sherman et al. 2009). The characteristics of a baby schema are often embodied in animals and inanimate objects, including products featuring representations of a cute, vulnerable living entity. Studies have also shown that customers' responses to cute products involve positive emotions and social behavior similar to responses to human infants (Nittono and Ihara 2017). Cuteness can be incorporated into robots as a visual design theme. We argue that perceiving a robot as cute will elicit the same response as a cute infant would. This instinct-based positive response will strengthen customers' intention to use the robot and will outweigh the importance of anthropomorphism

In contrast to humanoid or functional designs, an increasing number of robots are designed to imitate living creatures (Fong et al. 2003). Such zoonotic designs

Physically embodied robots $<$ nonphysically embodied robots

Female service robots $>$ nonfemale robots

(1)


Table 1 (continued)

\begin{tabular}{lll}
\hline Moderator & Theoretical explanation for expected relationship with estimates & Prediction \\
\hline
\end{tabular}

are typically inspired by household and wild animals, such as the Sony Aibo dog or the therapeutic seal robot Paro. Other robots feature a creaturelike design with no real-world counterpart. Research shows that customers consider these robots as zoomorphic creatures even when their physical aspect is obviously different from that of an animal (Friedman et al. 2003). The purpose of a robot's zoonotic design is to foster a relationship with customers. People assign to robotic pets attributes of living animals, such as having mental states, being a social other, and having a moral standing (Melson et al. 2009).

Moreover, the resemblance of zoonotic robots to vulnerable animals can attract customers' attention and caring responses (Coghlan et al. 2018). If people perceive zoonotic robots as companions, they provide emotional support and stimulate attachment and engagement (Coghlan et al. 2018), and therapeutic robot animals have effects on humans that are similar to those of therapy animals. Thus, the positive impact of zoonotic robots on customers' caring behavior will substitute the baby schema effect of anthropomorph robots

Humanoid design (H1f) The process of attributing human characteristics to nonliving agents such as service robots is enhanced if the nonliving entity is congruent with the human schema (Aggarwal and McGill 2012). One approach to enhance the perception of humanlike features is to design the robot in a human form. This implies humanlike parts of a robot's physical shape, the usage of facial expressions and other social cues, as well as natural humanlike interaction and communication (e.g. speech, gaze) (Fink 2012). As such service robots can vary in their humanoid appearance from no resemblance to humans (e.g., mechanical robots), to some body shape resemblance (e.g., biped humanoids) to a perfect copy of human body (e.g., androids) (Ferrari et al. 2016). Robots with a humanoid design typically feature the body shape analogous to that of a human being with a body, head, two arms, and two legs. This also allows for humanlike behavior through locomotion and manipulation capabilities similar to human beings ( $\mathrm{Yu}$ et al. 2014). Research has shown that robots with a humanoid design elicit social responses from humans (Powers and Kiesler 2006). We argue that a humanoid robot design elicits social perceptions of the robot and thus accelerates the process of attributing human characteristics to service robots. Thus, we propose that the positive impact of a humanoid design will strengthen the effect of anthropomorphic robots

Service context-related moderators

Critical services (H2a) Critical services are those that play an essential role for customers, such as booking hotel rooms, buying tickets, and banking. These services' importance to customers complicates the decision-making process when interacting with service robots (Belanche et al. 2020); customers worry that mistakes may happen, and focus on higher quality standards (Iaccobucci et al. 1995). Because services delivered by human personnel appear to be more tailored, customers may refrain from using robotic services in critical or risky encounters. However, research shows that customers use different strategies to deal with these uncertainties (Lussier and Olshavsky 1979), and that some customers reduce uncertainty by ascribing distinctive human characteristics to technologies (Burgoon et al. 2000). Thus, anthropomorphism will counteract the impulse to avoid service robots for critical services. In line with TTF, we assume that robot anthropomorphism will be a stronger predictor of use intention for critical services than noncritical services

Possession-processing Wirtz and Lovelock (2016) proposed a systematic grouping of service contexts services (H2b) according to the nature of the service object and the degree of intangibility

\section{Robots with a humanoid design $>$ nonhumanoid robots}

Possession-processing services $<$ nonpossession-processing services
Critical services $>$ noncritical services involved. Possession-processing services are tangible actions targeted at goods and other physical possessions belonging to the customer (Wirtz and Lovelock 2016), such as cleaning an apartment, freight transportation, goods storage, and laundry services. Here, the customer is less physically and mentally involved in the provision of the service (Wirtz and Lovelock 2016), which can be described as low-contact and mainly operates in the background. Customers are used to having little influence on such direct service provision, regardless of whether a service robot or a human service employee provides the service, and consequently see the process of task execution as less important than the outcome of the service provision (Burgoon et al. 2000). Customers can assess 
Table 1 (continued)

\begin{tabular}{|c|c|c|}
\hline Moderator & Theoretical explanation for expected relationship with estimates & Prediction \\
\hline & $\begin{array}{l}\text { the quality of service provision (e.g., the cleanliness of an apartment) only after } \\
\text { the service has been provided. Thus, robot anthropomorphism will play a } \\
\text { minor role for customers in these contexts because there is very little interac- } \\
\text { tion with the robot }\end{array}$ & \\
\hline $\begin{array}{l}\text { Information-processing } \\
\text { services }(\mathrm{H} 2 \mathrm{c})\end{array}$ & $\begin{array}{l}\text { Information-processing services, including banking and market research, are the } \\
\text { second service type directed at intangible customer assets (Wirtz and Lovelock } \\
\text { 2016). The services' intangibility and the lack of direct customer involvement } \\
\text { in service co-creation causes greater uncertainty for customers (Belanche et al. } \\
\text { 2020). Information-processing services (e.g., financial advice) are credence } \\
\text { services, and customers may be unsure how good the robot's service was. In } \\
\text { these contexts, the service robot's anthropomorphism may act as a cue that } \\
\text { reduces customer uncertainty (Ferrari et al. 2016). Since anthropomorphism is } \\
\text { useful for value co-creation therein, it gains importance as a predictor }\end{array}$ & $\begin{array}{l}\text { Information-processing services }> \\
\text { noninformation-processing services }\end{array}$ \\
\hline $\begin{array}{l}\text { People-processing } \\
\text { services }(\mathrm{H} 2 \mathrm{~d})\end{array}$ & $\begin{array}{l}\text { In people-processing services the customer is the direct recipient of tangible } \\
\text { services, for example in health care, restaurants, hotels, and passenger trans- } \\
\text { portation (Wirtz and Lovelock 2016). A characteristic of this type of service is } \\
\text { that the customer must visit or at least come into direct contact with the service } \\
\text { provider. Research shows that humanlike robots achieve higher customer ac- } \\
\text { ceptance rates for these services (Li et al. 2010). Additionally, "anthropo- } \\
\text { morphic interfaces incorporating animated characters, speech synthesis or AI } \\
\text { are more appropriate when collaborative encounters are desired in as much as } \\
\text { participants take a more active role in the interaction" (Burgoon et al. 2000, p. } \\
\text { 571) }\end{array}$ & $\begin{array}{l}\text { People-processing services }> \\
\quad \text { nonpeople-processing services }\end{array}$ \\
\hline $\begin{array}{l}\text { Mental } \\
\text { stimulus-processing } \\
\text { services (H2e) }\end{array}$ & $\begin{array}{l}\text { The fourth service type that Wirtz and Lovelock (2016) suggested covers mental } \\
\text { stimulus-processing services directed at the customer's mind, such as } \\
\text { education, entertainment, news, and information. In contrast to } \\
\text { people-processing services, here recipients need only be mentally present, and } \\
\text { there is less physical customer-service provider interaction (Li et al. 2010). } \\
\text { Anthropomorphism is more important for people-processing services and less } \\
\text { important for mental stimulus-processing services, because there is less } \\
\text { physical presence. As per TTF theory, we assume the influence of anthropo- } \\
\text { morphism on intention to use the robot will be weaker for this service type }\end{array}$ & $\begin{array}{l}\text { Mental stimulus-processing services }< \\
\text { nonmental stimulus-processing services }\end{array}$ \\
\hline \multicolumn{3}{|l|}{ Method moderators } \\
\hline \multicolumn{3}{|c|}{$\begin{array}{l}\text { We consider that student samples are rather similar in terms of interests and experiences compared to nonstudent samples. Thus, the error variance } \\
\text { measurement may be lower in student samples, leading to stronger effect sizes (Orsingher et al. 2009). We control for the influence of the stimuli used. } \\
\text { Some robot studies have argued that videos/images resemble real-life robot interactions (Ho and MacDorman 2010). Some have used field studies, } \\
\text { and others have relied on lab settings. Because experimental studies control for the influence of extraneous variables, they may display stronger effect } \\
\text { sizes (Iyer et al. 2020). We control for the potential of publication bias, assessing whether differences exist between published and unpublished } \\
\text { studies. Since studies were collected from two literature streams, we compare marketing versus HRI literature differences. We examine whether } \\
\text { studies published in journals differ from studies published elsewhere. We also examine whether country differences exist by comparing US and } \\
\text { non-US samples, and depending on the country's innovativeness, since customers in innovative countries have more experience with technological } \\
\text { innovations. Finally, we control for the influence of study year as customers may gain more experience over time }\end{array}$} \\
\hline
\end{tabular}

$>=$ effect of anthropomorphism on intention to use is stronger; $<=$ effect of anthropomorphism on intention to use is weaker

sample size to correct for sampling errors and calculated 95\% confidence intervals. We also calculated credibility intervals to indicate the distribution of effect sizes (Hunter and Schmidt 2004). We used the $\chi^{2}$ test of homogeneity to examine the effect size distribution (Hunter and Schmidt 2004); a significant result suggests substantial variation. To test for publication bias we used Rosenthal's (1979) fail-safe N (FSN), which represents the number of studies with null results that would be necessary to lower a significant relationship to a barely significant level $(p=.05)$. According to Rosenthal (1979), results are robust when FSN values are greater than $5 \times$ $k+10$, where $k$ equals the number of correlations. We complemented this test with funnel plots showing effect sizes on one axis and sample sizes on the other. An asymmetric funnel plot indicates publication bias. We also reported skewness statistics for effect sizes and the statistical power of our tests. We used moderator analysis and structural equation modeling in our meta-analysis. Web Appendix $\mathrm{C}$ gives more information about these multivariate analyses and the coding process of effects sizes and moderators. 


\section{Results}

\section{Results of effect size integration}

We found that service robot anthropomorphism was related to various antecedents, mediators, and outcomes (Table 2). First, six out of nine tested traits/predispositions and sociodemographic variables were related to anthropomorphism $(p<.05)$, with the strongest effects for competence (sample-weighted reliability-adjusted average correlation $[\mathrm{rc}]=.23)$, computer anxiety $(\mathrm{rc}=.20)$, and NARS $(\mathrm{rc}=.17)$. The effects of age $(\mathrm{rc}=-.12)$, customer gender $(\mathrm{rc}=.07)$, and prior experience $(\mathrm{rc}=.07)$ were weaker but still significant. We observed no significant effects for education, income, or need for interaction. We found physical robot features to display a stronger effect $(\mathrm{rc}=51)$ than nonphysical robot features $(\mathrm{rc}=.35)$. Among nonphysical features, emotions of the robot had the strongest effect (.69), followed by voice $(\mathrm{rc}=.33)$, gesture $(\mathrm{rc}=.26)$, and mimicry $(\mathrm{rc}=.25)$. The effect of gaze was nonsignificant.

Second, we found that anthropomorphism was related to all robot-related and functional mediators and to some relational mediators. We found significant effects for robot-related mediators, including animacy $(\mathrm{rc}=.85)$, intelligence $(\mathrm{rc}=.54)$, likability $(\mathrm{rc}=.53)$, safety $(\mathrm{rc}=.31)$, and social presence $(\mathrm{rc}=$ .23). Similarly, we found significant effects for functional mediators: ease of use $(\mathrm{rc}=.25)$ and usefulness $(\mathrm{rc}=.32)$. Further, we found that anthropomorphism was related to three relational mediators: positive affect $(\mathrm{rc}=.56)$, satisfaction $(\mathrm{rc}=.41)$, and trust $(\mathrm{rc}=.19)$. These results provisionally indicate some mediating effects. We observed no significant effects for negative affect or rapport.

Third, we assessed the influence of anthropomorphism on intention to use the robot in future. We found that anthropomorphism was strongly related to this outcome variable $(\mathrm{rc}=$ .35). ${ }^{3}$ Structural equation modeling (SEM) will therefore clarify the importance of indirect effects of anthropomorphism through mediators on this outcome relative to the direct effect.

The wide credibility intervals of many of these relationships suggest substantial variance in effect sizes. Moreover, the calculated Q-tests for homogeneity were significant in 18 out of 29 cases. For each significant averaged, reliabilitycorrected effect size, we calculated the FSN. Most FSNs (15 out of 23) exceeded the tolerance levels suggested by Rosenthal (1979), indicating results to be robust to publication bias. The calculated funnel plots were symmetric, further indicating that publication bias is unlikely to have affected our results. The skewness of effect sizes is similar to that of other meta-analyses (Otto et al. 2020). Most power values are larger

\footnotetext{
${ }^{3}$ We tested potential nonlinearity of this relationship but found it to be linear (Web Appendix C).
}

than .5 , suggesting that our tests have sufficient power to detect meaningful effect sizes (Blut et al. 2016).

\section{Results of SEM}

We tested our conceptual model using SEM, with the correlation matrix displayed in Web Appendix E as input. The matrix included 16 constructs of the meta-analytic framework, and we observed two high correlations. The first was between usefulness and intention to use; this was unsurprising, since usefulness is the key mediator in TAM, and many empirical studies on technology use have found similar effects (Davis et al. 1989). The second high correlation was between robot anthropomorphism and animacy. Again, this finding was unsurprising because of the aforementioned conceptual overlap of the two robot characteristics (Ho and MacDorman 2010). We addressed the issue of the high correlations by testing several alternative models without these variables. The results remained largely unchanged. ${ }^{4}$ The condition number of the calculated models ranged between 4.98 and 11.42; thus, multicollinearity was not a serious issue. The final results of the model tests are given in Table 3. We tested the mediating effects in three models, one for each set of mediating factors. ${ }^{5}$ Model 1 tests the mediating effects of the robot-related mediators, Model 2 shows the results for the functional mediators, and Model 3 reports the relational mediator results. Bergh et al. (2016, p. 478) explain that using SEM in meta-analysis "allows researchers to draw on accumulated findings to test the explanatory value of a theorized model against one or more competing models, thereby allowing researchers to conduct 'horse races' between competing frameworks." Our models displayed good fit, largely confirming the findings from the descriptive statistics. ${ }^{6}$

Regarding the antecedents of anthropomorphism, Models $1-3$ in Table 3 show that customer age $(\gamma=-.11, p<.05)$ and need for interaction $(\gamma=-.19, p<.05)$ were negatively related to anthropomorphism, whereas NARS was positively related to anthropomorphism $(\gamma=.21, p<.05)$. We observed no effects for customer gender, education, income, or anxiety. For the mediators of anthropomorphism, we found more support for robot-related mediators (Model 1) and functional mediators (Model 2) than for relational mediators (Model 3). Anthropomorphism displayed only a weak negative effect on rapport, contrary to expectations, whereas the effect of

\footnotetext{
${ }^{4}$ After removing animacy from Model 1 , the effects of anthropomorphism $(\beta=.20)$, intelligence $(\beta=.19)$, and safety $(\beta=.30)$ on intention remained unchanged. After removing usefulness from Model 2, we found that the effects of anthropomorphism $(\beta=.18)$ and ease of use $(\beta=.61)$ on use intention remained the same $(p<.05)$.

${ }^{5}$ We considered testing one full model with all mediators, but this model was too complex. However, some mediators can be integrated, such as usefulness, ease of use, and satisfaction, which is in line with IS literature.

${ }^{6}$ We tested the robustness by excluding nonsignificant relationships (Web Appendix F); results were unchanged.
} 


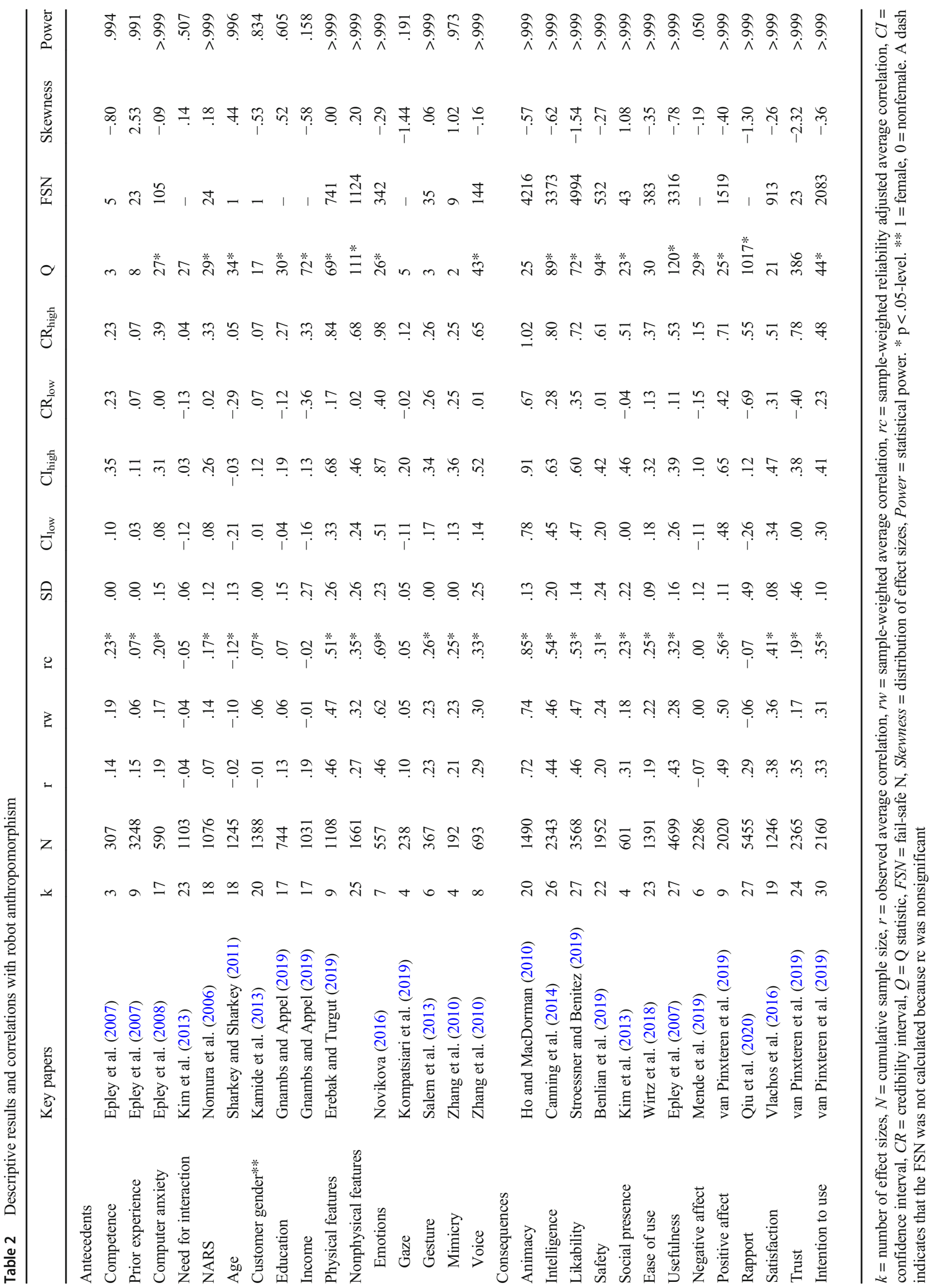


Table 3 Results of structural equation modeling

\begin{tabular}{|c|c|c|c|c|c|c|c|}
\hline \multirow[b]{2}{*}{ IV } & \multirow[b]{2}{*}{ DV } & \multicolumn{2}{|c|}{ Model 1: robot-related mediators } & \multicolumn{2}{|c|}{ Model 2: functional mediators } & \multicolumn{2}{|c|}{ Model 3: relational mediators } \\
\hline & & $\mathrm{B}$ & $\mathrm{p}$ & $\mathrm{B}$ & $\mathrm{p}$ & $\mathrm{B}$ & $\mathrm{p}$ \\
\hline \multicolumn{8}{|l|}{ Antecedents } \\
\hline Age & Anthropomorphism & $-.11^{*}$ & .00 & $-.11 *$ & .00 & $-.11^{*}$ & .00 \\
\hline Customer gender** & Anthropomorphism & .05 & .18 & .05 & .18 & .05 & .18 \\
\hline Education & Anthropomorphism & .07 & .06 & .07 & .06 & .07 & .06 \\
\hline Income & Anthropomorphism & -.03 & .40 & -.03 & .40 & -.03 & .40 \\
\hline Computer anxiety & Anthropomorphism & .10 & .07 & .10 & .07 & .10 & .07 \\
\hline NARS & Anthropomorphism & $.21 *$ & .00 & $.21 *$ & .00 & $.21 *$ & .00 \\
\hline Need for interaction & Anthropomorphism & $-.19 *$ & .00 & $-.19 *$ & .00 & $-.19 *$ & .00 \\
\hline \multicolumn{8}{|l|}{ Mediators } \\
\hline Anthropomorphism & Intelligence & $.55^{*}$ & .00 & - & & - & \\
\hline Age & Intelligence & .00 & .99 & - & & - & \\
\hline Customer gender** & Intelligence & .03 & .34 & - & & - & \\
\hline Education & Intelligence & $-.13 *$ & .00 & - & & - & \\
\hline Income & Intelligence & $.24 *$ & .00 & - & & - & \\
\hline Computer anxiety & Intelligence & $-.15^{*}$ & .00 & - & & - & \\
\hline NARS & Intelligence & $.18^{*}$ & .00 & - & & - & \\
\hline Need for interaction & Intelligence & -.05 & .17 & - & & - & \\
\hline Anthropomorphism & Safety & $.42 *$ & .00 & - & & - & \\
\hline Age & Safety & .01 & .71 & - & & - & \\
\hline Customer gender** & Safety & $-.10 *$ & .00 & - & & - & \\
\hline Education & Safety & $-.14^{*}$ & .00 & - & & - & \\
\hline Income & Safety & $.26^{*}$ & .00 & - & & - & \\
\hline Computer anxiety & Safety & $-.60^{*}$ & .00 & - & & - & \\
\hline NARS & Safety & $.18^{*}$ & .00 & - & & - & \\
\hline Need for interaction & Safety & -.07 & .07 & - & & - & \\
\hline Anthropomorphism & Animacy & $.93 *$ & .00 & - & & - & \\
\hline Age & Animacy & $.03 *$ & .04 & - & & - & \\
\hline Customer gender** & Animacy & -.02 & .17 & - & & - & \\
\hline Education & Animacy & -.02 & .15 & - & & - & \\
\hline Income & Animacy & $.24 *$ & .00 & - & & - & \\
\hline Computer anxiety & Animacy & $-.22 *$ & .00 & - & & - & \\
\hline NARS & Animacy & $-.13^{*}$ & .00 & - & & - & \\
\hline Need for interaction & Animacy & $.08^{*}$ & .00 & - & & - & \\
\hline Anthropomorphism & Ease of use & - & & $.39^{*}$ & .00 & - & \\
\hline Age & Ease of use & - & & $-.07 *$ & .01 & - & \\
\hline Customer gender** & Ease of use & - & & -.01 & .81 & - & \\
\hline Education & Ease of use & - & & .06 & .06 & - & \\
\hline Income & Ease of use & - & & $.08 *$ & .02 & - & \\
\hline Computer anxiety & Ease of use & - & & $-.16^{*}$ & .00 & - & \\
\hline NARS & Ease of use & - & & $-.54 *$ & .00 & - & \\
\hline Need for interaction & Ease of use & - & & $.43 *$ & .00 & - & \\
\hline Anthropomorphism & Usefulness & - & & $.14 *$ & .00 & - & \\
\hline Ease of use & Usefulness & - & & $.51 *$ & .00 & - & \\
\hline Age & Usefulness & - & & .00 & .92 & - & \\
\hline Customer gender** & Usefulness & - & & .01 & .72 & - & \\
\hline Education & Usefulness & - & & $.08 *$ & .01 & - & \\
\hline Income & Usefulness & - & & $.08^{*}$ & .01 & - & \\
\hline
\end{tabular}


Table 3 (continued)

\begin{tabular}{|c|c|c|c|c|c|c|c|}
\hline \multirow[b]{2}{*}{ IV } & \multirow[b]{2}{*}{ DV } & \multicolumn{2}{|c|}{ Model 1: robot-related mediators } & \multicolumn{2}{|c|}{ Model 2: functional mediators } & \multicolumn{2}{|c|}{ Model 3: relational mediators } \\
\hline & & $\mathrm{B}$ & $\mathrm{p}$ & $\mathrm{B}$ & $\mathrm{p}$ & $\mathrm{B}$ & $\mathrm{p}$ \\
\hline Computer anxiety & Usefulness & - & & $.50 *$ & .00 & - & \\
\hline NARS & Usefulness & - & & $-.30 *$ & .00 & - & \\
\hline Need for interaction & Usefulness & - & & .06 & .12 & - & \\
\hline Anthropomorphism & Rapport & - & & - & & $-.08^{*}$ & .01 \\
\hline Age & Rapport & - & & - & & -.03 & .38 \\
\hline Customer gender** & Rapport & - & & - & & $.13 *$ & .00 \\
\hline Education & Rapport & - & & - & & $.36^{*}$ & .00 \\
\hline Income & Rapport & - & & - & & $-.20 *$ & .00 \\
\hline Computer anxiety & Rapport & - & & - & & $.58 *$ & .00 \\
\hline NARS & Rapport & - & & - & & $-.77 *$ & .00 \\
\hline Need for interaction & Rapport & - & & - & & $.36^{*}$ & .00 \\
\hline Anthropomorphism & Satisfaction & - & & - & & $.44 *$ & .00 \\
\hline Age & Satisfaction & - & & - & & -.03 & .42 \\
\hline Customer gender** & Satisfaction & - & & - & & .06 & .07 \\
\hline Education & Satisfaction & - & & - & & $.10 *$ & .00 \\
\hline Income & Satisfaction & - & & - & & -.07 & .07 \\
\hline Computer anxiety & Satisfaction & - & & - & & $.18^{*}$ & .00 \\
\hline NARS & Satisfaction & - & & - & & $-.43 *$ & .00 \\
\hline Need for interaction & Satisfaction & - & & - & & $.20 *$ & .00 \\
\hline \multicolumn{8}{|l|}{ Consequences } \\
\hline Anthropomorphism & Intention to use & $.20^{*}$ & .00 & $.12 *$ & .00 & $.28 *$ & .00 \\
\hline Intelligence & Intention to use & $.19^{*}$ & .00 & - & & - & \\
\hline Safety & Intention to use & $.30 *$ & .00 & - & & - & \\
\hline Animacy & Intention to use & - & & - & & - & \\
\hline Usefulness & Intention to use & - & & $.71 *$ & .00 & - & \\
\hline Ease of use & Intention to use & - & & $.18 *$ & .00 & - & \\
\hline Rapport & Intention to use & - & & - & & $.66^{*}$ & .00 \\
\hline Satisfaction & Intention to use & - & & - & & $.44 *$ & .00 \\
\hline Customer gender** & Intention to use & - & & - & & $-.08^{*}$ & .00 \\
\hline Education & Intention to use & $.10 *$ & .00 & - & & - & \\
\hline Income & Intention to use & - & & - & & $.10^{*}$ & .00 \\
\hline Computer anxiety & Intention to use & - & & $-.22 *$ & .00 & $-.30^{*}$ & .00 \\
\hline NARS & Intention to use & $-.30 *$ & .00 & - & & - & \\
\hline Need for interaction & Intention to use & - & & $-.13 *$ & .00 & $-.10 *$ & .00 \\
\hline Goodness-of-fit inde & & .898 & & .996 & & .918 & \\
\hline Normed fit index & & .796 & & .995 & & .882 & \\
\hline Root mean square re & idual (RMR) & .041 & & .010 & & .025 & \\
\hline Standardized RMR & & .041 & & .010 & & .026 & \\
\hline
\end{tabular}

$* p<.05 . * * 1=$ female, $0=$ nonfemale. Harmonic mean: 883 . We considered direct effects of antecedents on intention to use when the effects were in line with expectations

anthropomorphism on other mediators was stronger and positive. Specifically, anthropomorphism was positively related to robot intelligence $(\beta=.55, p<.05)$, safety $(\beta=.42$, $p<.05)$, and animacy $(\beta=.93, p<.05)$. Again, the effect on robot animacy was the strongest among the examined mediators (Model 1). We also found that anthropomorphism was positively related to service robot ease of use $(\beta=.39$, $p<.05)$ and usefulness $(\beta=.14, p<.05)$, as shown in Model 2 . Finally, we found that anthropomorphism was negatively related to rapport ( $\beta=-.08, p<.05$ ), contrary to predictions; however, this effect was small. Among the relational mediators, we observed a strong effect only on satisfaction $(\beta=.44$, 
$p<.05)$. In all three models, we found anthropomorphism to be positively related to intention to use the robot ( $\beta$ values ranging from .12 to $.28, p<.05$ ). Thus, when including the direct effects of mediators on this outcome, anthropomorphism had a significant effect, indicating partial mediation. We report the indirect and total effects of Models 1-3 in Web Appendix G.

\section{Moderator analysis}

\section{Results of subgroup analysis}

Table 4 shows the moderator tests for the anthropomorphismintention to use relationship. Because we only have 30 effect sizes for this relationship, we first conducted subgroup analysis before using regression analysis. As shown, we found significant differences for moderators describing the type of service robot and type of service. Four method moderators were significant. Specifically, we found that anthropomorphism had a weaker effect on intention to use for physical than for nonphysical robots (H1a: $\mathrm{rc}_{\text {physical }}=.30 \mathrm{vs}$. $\mathrm{rc}_{\text {nonphysical }}=.38$, $p<.05)$ and stronger effects for female than for nonfemale robots $\left(\mathrm{H} 1 \mathrm{~b}: \mathrm{rc}_{\text {female }}=.52 \mathrm{vs} . \mathrm{rc}_{\text {nonfemale }}=.31, p<.05\right)$. Further, the effects were stronger for provision of critical than for noncritical services $\left(\mathrm{H} 2 \mathrm{a}: \mathrm{rc}_{\text {critical }}=.43 \mathrm{vs} . \mathrm{rc}_{\text {noncritical }}=.30\right.$, $p<.05)$. We found weaker effects when comparing possession-processing with nonpossession-processing services $\left(\mathrm{H} 2 \mathrm{~b}: \mathrm{rc}_{\text {possession }}=.17\right.$ vs. $\left.\mathrm{rc}_{\text {nonpossession }}=.36, p<.05\right)$ and mental stimulus-processing with nonmental stimulusprocessing services $\left(\mathrm{H} 2 \mathrm{e}: \mathrm{rc}_{\text {mental }}=.28\right.$ vs. $\mathrm{rc}_{\text {nonmental }}=.42$, $p<.05)$. However, we found stronger effects for information-processing compared to noninformationprocessing services $\left(\mathrm{H} 2 \mathrm{c}: \mathrm{rc}_{\text {information }}=.49 \mathrm{vs}\right.$. $\mathrm{rc}$ noninformation $=.30, p<.05)$. Among the method moderators, we found significant differences for publication outlet, publication status, and marketing journal. The effects were weaker in studies published in journals $\left(\mathrm{rc}_{\text {journal }}=.29\right.$ vs. rcnonjournal $=.43, p<.05)$ and in published rather than unpublished studies $\left(\mathrm{rc}_{\text {published }}=.31\right.$ vs. $\left.\mathrm{rc}_{\text {unpublished }}=.57, p<.05\right)$. They were stronger in marketing than in HRI journals (rcmarketing $=.39$ vs. $\left.\mathrm{rc}_{\mathrm{HRI}}=.32, p<.05\right)$. Further, the continuous moderator study year was positively correlated with effect sizes $(\mathrm{r}=.58, p<.05)$, suggesting stronger effects in later studies. The other moderators were nonsignificant. ${ }^{7}$

\section{Results of metaregression}

We validated these results using a metaregression (Grewal et al. 2018) in which we regressed the effect sizes on the 10 moderators significant in the subgroup analysis (Table 5). We

\footnotetext{
${ }^{7}$ Although outside the scope of this paper, we calculated subgroup analysis for mediators (Web Appendix H).
}

observed stronger effects for female than nonfemale robots (H1b: $\beta=.16, p<.05)$. We found weaker effects for possession-processing than nonpossession-processing services $(\mathrm{H} 2 \mathrm{~b}: \beta=-.25, p<.05)$ and for mental stimulusprocessing than nonmental stimulus-processing services (H2e: $\beta=-.10, p<.10)$. Also, the effects were stronger in later studies because study year was significant $(\beta=.06$, $p<.05$ ). The direction of these moderating effects was in line with results of the subgroup analysis. ${ }^{8}$ No differences were observed for other moderators. The moderators explained $73 \%$ of the variance in effect sizes. In addition, multicollinearity among the moderator variables was low, the largest variance inflation factor (VIF) being 6.910 . Figure 2 summarizes the results of the SEM and metaregression.

\section{Discussion}

The present meta-analysis enhances understanding of service robot anthropomorphism. We developed and tested a comprehensive framework of antecedents, outcomes, and context variables relating to the impact of anthropomorphism on intention to use a service robot. By developing and testing such a comprehensive meta-analytic model, our study clarifies the role of anthropomorphism in customer use intention of robot technology, its underlying mechanisms, and the influence of contextual moderators. The findings provide new insights and raise questions for future research. First, it was initially unclear whether anthropomorphism exerts a positive or negative effect on customer intention to use a robot. This study clarifies that anthropomorphism exerts a strong positive effect (Tables 2 and 3), as anthropomorphism theory suggests (Duffy 2003). It seems that humanlike perceptions are more likely to facilitate human-robot interactions, helping customers to apply the familiar social rules and expectations of human-human interactions (Zlotowski et al. 2015). This finding emphasizes that robot anthropomorphism is important for service scholars studying customer interaction with this technology. We recommend that scholars employ anthropomorphism theory more often, since it explains customer reactions to service robots better than does uncanny valley theory.

Second, we clarify the mediating mechanisms between robot anthropomorphism and customer use intention. Following Bergh et al. (2016), we used meta-analysis to carry out a "horse race" and examine the explanatory power of one theoretical model versus competing models (Tables 2 and 3). We found that five major robot characteristics proposed by HRI research represent important robot-related mediators

\footnotetext{
${ }^{8}$ Given the importance of these moderator variables, we also assessed their influence using multi-group SEM (Web Appendix I), but we do not discuss the results in this paper.
} 
Table 4 Moderator tests for the anthropomorphism-intention to use relationship. Results of random effects ANOVA

\begin{tabular}{|c|c|c|c|}
\hline \multirow[b]{2}{*}{ Moderator } & \multicolumn{3}{|l|}{ Level of moderator } \\
\hline & $\mathrm{rc}_{\text {high }}$ & $\mathrm{rc}_{\text {low }}$ & $\Delta \mathrm{rc}$ \\
\hline \multicolumn{4}{|l|}{ Type of service robot } \\
\hline \multirow[t]{2}{*}{ Physical (nonphysical) } & $.30 *$ & $.38 *$ & $-.08 *$ \\
\hline & $\mathrm{k}=19 ; N=828$ & $\mathrm{k}=11 ; N=1332$ & $\mathrm{Q}_{\mathrm{B}}=5.536$ \\
\hline \multirow[t]{2}{*}{ Female gender (nonfemale) } & $.52 *$ & $.31 *$ & $.21 *$ \\
\hline & $\mathrm{k}=5 ; N=407$ & $\mathrm{k}=25 ; N=1753$ & $\mathrm{Q}_{\mathrm{B}}=9.543$ \\
\hline \multirow[t]{2}{*}{ Large size (nonlarge) } & $.38^{*}$ & $34 *$ & .04 \\
\hline & $\mathrm{k}=10 ; N=408$ & $\mathrm{k}=20 ; N=1752$ & $\mathrm{Q}_{\mathrm{B}}=.050$ \\
\hline \multirow[t]{2}{*}{ Cute (noncute) } & $.31^{*}$ & $.37^{*}$ & -.06 \\
\hline & $\mathrm{k}=10 ; N=525$ & $\mathrm{k}=20 ; N=1635$ & $\mathrm{Q}_{\mathrm{B}}=2.202$ \\
\hline \multirow[t]{2}{*}{ Zoonotic (nonzoonotic) } & $.35^{*}$ & $.35^{*}$ & .00 \\
\hline & $\mathrm{k}=4 ; N=134$ & $\mathrm{k}=26 ; N=2026$ & $\mathrm{Q}_{\mathrm{B}}=.062$ \\
\hline \multirow[t]{2}{*}{ Humanoid robot (nonhumanoid) } & $.36^{*}$ & $.33^{*}$ & .03 \\
\hline & $\mathrm{k}=17 ; N=1726$ & $\mathrm{k}=13 ; N=434$ & $\mathrm{Q}_{\mathrm{B}}=.702$ \\
\hline \multicolumn{4}{|l|}{ Type of service } \\
\hline \multirow[t]{2}{*}{ Critical (noncritical) } & $.43^{*}$ & $.30 *$ & $.13^{*}$ \\
\hline & $\mathrm{k}=19 ; N=816$ & $\mathrm{k}=11 ; N=1344$ & $\mathrm{Q}_{\mathrm{B}}=3.951$ \\
\hline \multirow[t]{2}{*}{ Possession-processing (nonpossession-processing) } & $.17 *$ & $.36^{*}$ & $-.19 *$ \\
\hline & $\mathrm{k}=4 ; N=132$ & $\mathrm{k}=26 ; N=2028$ & $\mathrm{Q}_{\mathrm{B}}=4.387$ \\
\hline \multirow[t]{2}{*}{ People-processing (nonpeople-processing) } & $.44^{*}$ & $.34 *$ & .10 \\
\hline & $\mathrm{k}=5 ; N=238$ & $\mathrm{k}=25 ; N=1922$ & $\mathrm{Q}_{\mathrm{B}}=1.064$ \\
\hline \multirow[t]{2}{*}{ Mental stimulus (nonmental stimulus) } & $.28 *$ & $.42 *$ & $-.14 *$ \\
\hline & $\mathrm{k}=9 ; N=1043$ & $\mathrm{k}=21 ; N=1117$ & $\mathrm{Q}_{\mathrm{B}}=4.594$ \\
\hline \multirow[t]{2}{*}{ Information-processing (noninformation) } & $.49 *$ & $.30 *$ & $.19 *$ \\
\hline & $\mathrm{k}=11 ; N=560$ & $\mathrm{k}=19 ; N=1600$ & $\mathrm{Q}_{\mathrm{B}}=9.924$ \\
\hline \multicolumn{4}{|l|}{ Method moderators } \\
\hline \multirow[t]{2}{*}{ Student sample (nonstudent sample) } & $.28 *$ & $.37^{*}$ & -.09 \\
\hline & $\mathrm{k}=4 ; N=395$ & $\mathrm{k}=26 ; N=1765$ & $\mathrm{Q}_{\mathrm{B}}=3.791$ \\
\hline \multirow[t]{2}{*}{ Video/image as stimuli (nonvideo/image as stimuli) } & $.32 *$ & $.39^{*}$ & -.07 \\
\hline & $\mathrm{k}=20 ; N=1233$ & $\mathrm{k}=10 ; N=927$ & $\mathrm{Q}_{\mathrm{B}}=.301$ \\
\hline \multirow[t]{2}{*}{ Field study (nonfield study) } & $.37 *$ & $.35^{*}$ & .02 \\
\hline & $\mathrm{k}=2 ; N=301$ & $\mathrm{k}=28 ; N=1859$ & $\mathrm{Q}_{\mathrm{B}}=.001$ \\
\hline \multirow[t]{2}{*}{ Published in journal (published in other publication) } & $.29 *$ & $.43 *$ & $-.14 *$ \\
\hline & $\mathrm{k}=19 ; N=1244$ & $\mathrm{k}=11 ; N=916$ & $\mathrm{Q}_{\mathrm{B}}=19.17$ \\
\hline \multirow[t]{2}{*}{ Published study (unpublished study) } & $.31 *$ & $.57 *$ & $-.26^{*}$ \\
\hline & $\mathrm{k}=24 ; N=1218$ & $\mathrm{k}=6 ; N=942$ & $\mathrm{Q}_{\mathrm{B}}=22.554$ \\
\hline \multirow[t]{2}{*}{ Marketing journal (HRI journal) } & $.39 *$ & $.32 *$ & $.07 *$ \\
\hline & $\mathrm{k}=9 ; N=1048$ & $\mathrm{k}=21 ; N=1112$ & $\mathrm{Q}_{\mathrm{B}}=6.399$ \\
\hline \multirow[t]{2}{*}{ USA as country (other country) } & $.40^{*}$ & $.28^{*}$ & .12 \\
\hline & $\mathrm{k}=25 ; N=1251$ & $\mathrm{k}=5 ; N=909$ & $\mathrm{Q}_{\mathrm{B}}=2.920$ \\
\hline \multirow[t]{2}{*}{ Country innovativeness ${ }^{\mathrm{a}}$} & $\mathrm{r}=.17$ & & \\
\hline & $p=.384$ & & \\
\hline \multirow[t]{2}{*}{ Study year ${ }^{\mathrm{a}}$} & $\mathrm{r}=.58^{*}$ & & \\
\hline & $p=.001$ & & \\
\hline
\end{tabular}

$* \mathrm{p}<.05 . \mathrm{k}=$ number of effect sizes; $\mathrm{N}=$ cumulative sample size. $\mathrm{Q}_{\mathrm{B}}=\mathrm{Chi}^{2}$ test for group means differences. $\mathrm{a}$. We correlated continuous moderators with effect sizes, as suggested by Hunter and Schmidt (2004) 


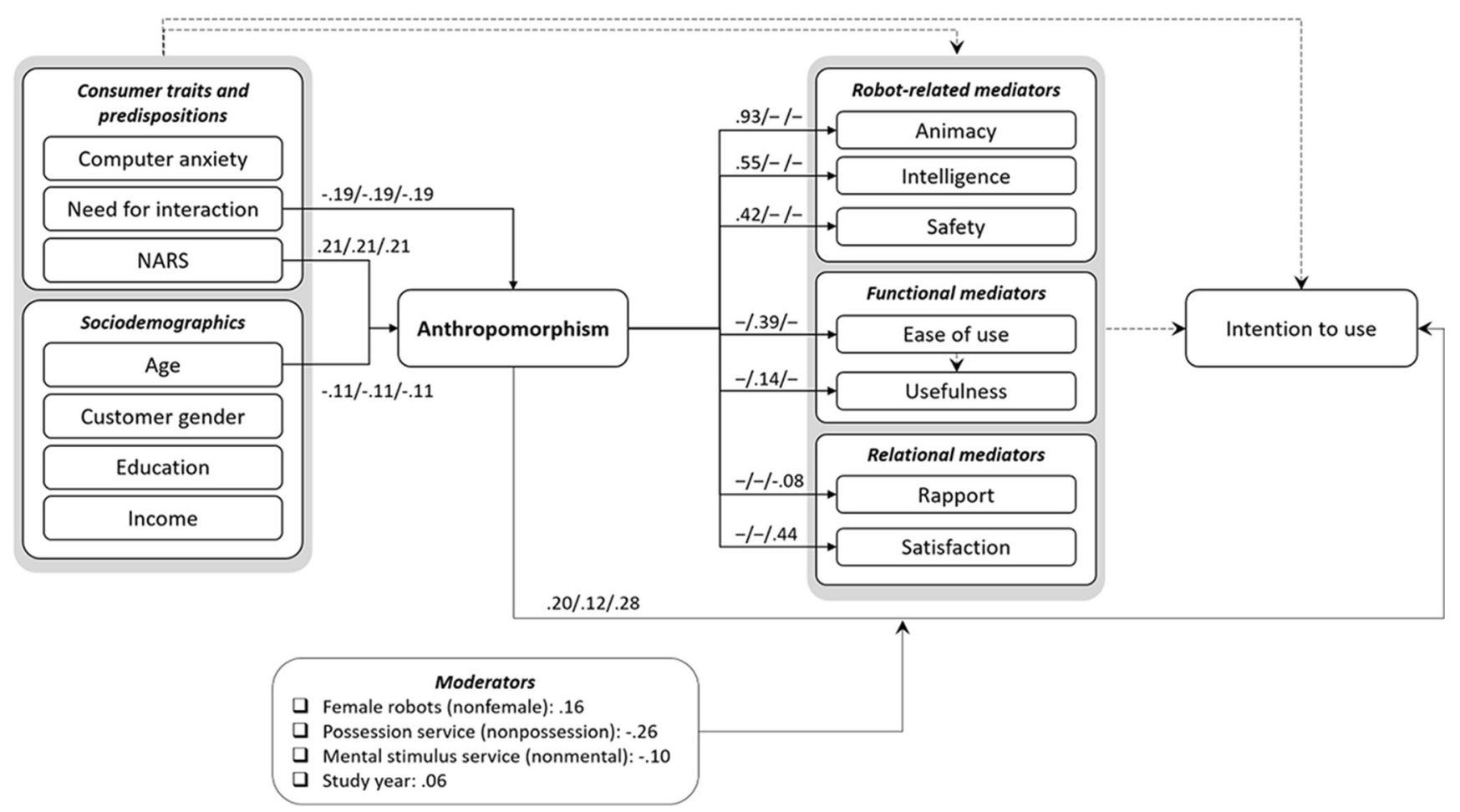

Fig. 2 Overview of key meta-analytic findings on robot anthropomorphism. Notes: The figure shows the results of SEM and metaregression (including significant relationships between anthropomorphism and other constructs only). The estimates refer to different SEM models (Model 1/

(Bartneck et al. 2009). Specifically, the robot characteristics of animacy, intelligence, likability, safety, and social presence are vital mediators, which elucidates the mechanisms by which anthropomorphism translates into future use intention. Similarly, we found that the two functional mediators proposed by technology acceptance research - usefulness and ease of use - are essential for understanding the operating mechanism of anthropomorphism (Davis et al. 1989). These mediators have received extensive attention in the technology acceptance and service literature, and our study clarifies their importance for service robots; recently developed models, such as the service robot acceptance model (Wirtz et al. 2018), should therefore be extended regarding these mediating effects. We also tested several relational mediators from the relationship marketing literature, but found less support for them (Tables 2 and 3). Although robot anthropomorphism is related to customer satisfaction and positive affect, its relationship with negative affect was nonsignificant and the relationship with rapport was negative. Scholars should therefore rethink the measurement of these mediators in service robot contexts. It may be that more specific relational mediators are required and that researchers need to specify the kinds of negative feelings that anthropomorphism may induce (e.g., tension, worry). Similarly, rapport may be induced by robot anthropomorphism only when interacting with a robot over a longer period, necessitating longitudinal research designs. The
Model 2/Model 3). All estimates are significant at the .05-level, except mental stimulus-processing services which is significant at the .10-level. The dotted lines suggest further significant relationships (not shown here to ease readability)

model comparison of our meta-analysis provides insights into not only the existence of mediating mechanisms but also their order, direction, and magnitude (Bergh et al. 2016). Unless they consider the mediators identified here, scholars will not fully understand why customers use service robots and may overestimate or underestimate the importance of anthropomorphism.

Third, we assessed the moderators influencing the anthropomorphism-intention to use relationship using metaregression (Table 5). We considered two sets of contextual moderators and one set of method moderators, and found differences depending on the type of robot employed by the service firm. Anthropomorphism had stronger effects for female than for nonfemale robots. Scholars should extend these findings to assess, for instance, how female customers react to male robots and vice versa. Regarding service type, we observed several factors influencing the importance of anthropomorphism as a predictor of use intention. We found Wirtz and Lovelock's (2016) service classification useful in this context. Specifically, anthropomorphism is more important for information-processing than for possession-processing and mental stimulus-processing services. We used tasktechnology fit theory to justify these effects. Scholars are therefore encouraged to apply established concepts in the service literature (e.g., service recovery) to robot research. The moderator results were robust when considering the influence 
Table 5 Moderator tests for the anthropomorphism-intention to use relationship. Results of random effects meta-regression

\begin{tabular}{llll}
\hline Moderator & B & SE & $\mathrm{p}$ \\
\hline Constant & $.70^{*}$ & .17 & .00 \\
Physical robot (nonphysical) & .01 & .07 & .43 \\
Female robot gender (nonfemale) & $.16^{*}$ & .07 & .01 \\
Critical service (noncritical) & .01 & .13 & .48 \\
Possession-processing service (nonpossession) & $-.26^{*}$ & .13 & .02 \\
Mental stimulus-processing service (nonmental stimulus) & $-.10 \dagger$ & .07 & .09 \\
Information-processing service (noninformation) & -.11 & .12 & .19 \\
Published in journal (published in other publication) & -.01 & .08 & .43 \\
Published study (unpublished study) & -.15 & .14 & .15 \\
Marketing journal (HRI journal) & -.11 & .10 & .12 \\
Study year & $.06^{*}$ & .03 & .01 \\
\hline
\end{tabular}

$* \mathrm{p}<.05 ; \dagger \mathrm{p}<.10$ (one-tailed), $\mathrm{k}=30, \max \mathrm{VIF}=6.910$. The table displays unstandardized regression coefficients. A positive (negative) regression coefficient indicates a stronger (weaker) positive relationship between anthropomorphism and intention to use when the moderator is high than when it is low. For example, the negative coefficient of possession-processing service indicates that the positive relationship between anthropomorphism and intention to use is weaker for possession-processing service than nonpossession-processing service. According to Albers et al. (2010), interpretation of the regression constant is meaningful since it represents a bias-corrected estimate of the baseline effect for the relationship of interest. Thus, we ran one regression considering only the four method characteristics; the method bias-corrected estimate is .67 of method moderators such as publication outlet and status, marketing journal, and study year. Regarding the latter moderator, it seems that anthropomorphism gained importance as a predictor of use intention in recent years. While some of the other robot and service type moderators were significant in subgroup analysis (Table 4), they were nonsignificant in meta-regression.

Fourth, we assessed the antecedents of anthropomorphism in order to understand which customers were more likely to anthropomorphize service robots (Table 3 ). The literature recognizes that customers anthropomorphize all kinds of marketing objects, including brands, products, and services; we contribute to this literature by testing the influence of various customer characteristics on robot anthropomorphism. We found that NARS, need for interaction, and customer age in particular are related to robot anthropomorphism. Some antecedents have only been assessed in descriptive statistics (Table 2); these analyses suggest further effects of customer competence, prior experience, and different physical and nonphysical robot features, such as gesture, mimicry, and voice of the robot. We explain these effects using Epley et al.'s (2007) theory of anthropomorphism, which is useful for analyzing why some customers are more likely than others to anthropomorphize robots.

\section{Managerial implications}

This meta-analysis has several implications for marketing managers intending to employ service robots on the front line and adhering to "honest or ethical anthropomorphism" (Leong and Selinger 2019; Thomaz et al. 2020) - the design of robot features to resemble human body/behavior with no intention to deliberately mislead users. First, our findings highlight to managers the potential consequences of employing humanlike versus machinelike robots in service firms. Since we found mainly positive effects associated with anthropomorphized service robots, managers should not worry that an uncanny valley effect will lead customers to decline to use service robots. Anthropomorphism is positively related to important outcomes including ease of use, usefulness, safety perception, and social presence, and it does not lead to the experience of negative affect. However, anthropomorphism is not positively related to rapport, which indicates that service robots may not (yet) develop a personal connection with customers (Wirtz et al. 2018). Therefore, when personal connection is key to a firm's business model, managers should employ human employees together with service robots. Managers can use the framework of this meta-analysis to comprehensively assess the reactions of various customers to service robots in customer surveys and focus groups.

Second, our meta-analysis helps managers to establish the service contexts in which it is most important to employ humanlike versus machinelike robots. Managers should employ humanlike robots for critical services including ticket selling and shopping advice in retailing; for uncritical services, robot anthropomorphism is less important. Similarly, humanlike robots should be employed for information-processing services such as banking and financial services; anthropomorphism is less important for encouraging customers to use robots for possession-processing or mental stimulus-processing 
services. Managers in the latter industries therefore have less need to invest in humanlike service robots and monitoring customer-robot interaction.

Third, our results will guide managers on which humanlike robots to choose when offering services to customers. We suggest that service firms employ female gendered rather than male gendered service robots (e.g., robots with a female look, name, and voice). However, managers can choose any robot size, level of cuteness, and even zoonotic body form, since no differences were observed for these robot types.

Fourth, managers can use these findings to identify which target customers are most receptive to the employment of humanlike robots. They should pay particular attention to customer traits and predispositions, including customer anxiety, negative attitude toward robots, and competence in using technology, and we recommend that they complement these criteria with sociodemographic variables such as customer age and gender. However, education, income, and need for interaction are less important for segmenting and targeting potential customers of robot services. Managers can also use our findings to assess whether their own customer base is ready for robot services. Finally, the results reveal which robots are most likely to be anthropomorphized by customers depending on different physical and nonphysical robot features (e.g., gesture, mimicry).

\section{Future research agenda}

While our discussion section provides insights on concepts that have already been explored in the context of anthropomorphism ("what we already know"), this section will focus on themes that have been neglected by extant literature ("what we do not know, but should know"). Table 6 presents exciting avenues for future research derived from the findings of our study and the lack of studies in current body of literature.

\section{Consider novel and untested outcomes}

We find support for the idea that anthropomorphism positively impacts intention to use the robot. As this research field is still developing, there are many interesting avenues for research that have not been fully explored. In particular, we could not explore relationships between anthropomorphism and outcome variables including willingness to pay for a service or purchase behavior, since such data is lacking. Thus, we urge future research to explore other outcomes of anthropomorphism beyond use intention that are relevant in a marketing context. For example, perceptions of a service robot may spill over to the firm or brand that employs the robot. Research has just begun to explore how service robots' perceptions impact perceptions such as brand trust and brand experience (Blut et al. 2018; Chan and Tung 2019). Research shows that if other humans are unavailable, and customers feel isolated, they will be more accepting of brands as sources of affiliation (Mazodier et al. 2018). Future studies should explore the role of brands in services delivered by robots, including the service robot-brand fit or alignment. Moreover, it would be interesting to assess nontraditional outcomes from transformative research such as customer literacy, loneliness, and learning as well as outcomes that may not be intended by managers, but are hampering customers' well-being (Schneider et al. 2019). Thomaz et al. (2020) proposed that technology with humanlike features has the potential to nudge customers toward greater self-disclosure. It also can lead to a decrease in selfcontrol, for example in consuming unhealthy products (Hur et al. 2015). Future studies should explore these and other "dark-side" effects, such as the impact of anthropomorphism on customer vulnerability and self-image. In addition, firms may use robots rather than employees for services such as complaint management. Beyond that, future research should address the following questions: Will service robots prevail in future as substitutes of human service providers, or will they augment a personally delivered service? Will customers use nonhuman service delivery across whole sectors, such as health care? How will this change customer expectations toward service quality?

\section{Test theoretically meaningful mediators}

We identified robot characteristics, functional characteristics, and some relational characteristics as important mediators in our model, as suggested in the marketing and HRI literature. We limited our analysis to mediators reported in extant studies. Scholars should build on this by carefully selecting and testing other meaningful mediators, such as different types of negative affect (e.g., tension, worry, and anger) and commitment (e.g., affective and calculative). In addition, it would be interesting to assess serial mediation in robot acceptance models (e.g., functional mediators impacting relational mediators), since these models were too complex for our SEM. These studies should also consider nonlinear effects of mediators on intention to use, although the nonlinear effect in our study was nonsignificant. Perhaps models considering novel mediators would display the expected nonlinear effects.

\section{Broaden the scope of antecedents and test their interactions}

We found robot design features and some customer characteristics to impact the extent to which customers anthropomorphize service robots. We could not differentiate between physical robot features (e.g., head, eyes, arms, legs), nor could we test interactions between these and other design features and customer characteristics. Future studies should also use Epley et al.'s (2007) theory of anthropomorphism, as per our study, and assess the antecedents of elicited agent knowledge, effectance motivation, and sociality motivation proposed in 
Table 6 Agenda for research on service robot anthropomorphism

Theme/issue Key illustrative recommendations

1. Consider novel and untested outcomes

2. Test theoretically meaningful mediators

4. Consider novel moderators and more complex moderating effects

6.Use different research designs interactions different service contexts
Examine the effects of service robot anthropomorphism on new outcomes (e.g., perceptions of human coworker, willingness to pay for the service, firm performance) and untested outcomes (e.g., actual technology use)

Examine the effect of service robots on brand image and brand experience (e.g., through service robot-brand fit)

Assess nontraditional outcomes from transformative research (e.g., literacy, loneliness, health, learning, and happiness)

Examine "dark-side" effects of service robot anthropomorphism (e.g., on customer vulnerability, self-image, willingness to self-disclose, loss of self-control) that hamper customer well-being

Explore industry-level outcomes (e.g., percentage of robot use across industries and substitution of human service providers)

Examine how robot anthropomorphism impacts customer responses to service failures (e.g., interactional, distributive, and procedural justice)

Test alternative conceptualizations and measurements for relational mediators such as kinds of negative affect (e.g., tension, worry, anger) and commitment (affective and calculative)

Assess serial mediation in robot acceptance models (e.g., functional mediators impacting relational mediators)

Assess nonlinear effects of mediators on intention to use

3. Broaden the scope of antecedents and test their Use Epley et al.'s (2007) theory of anthropomorphism to study antecedents of robot anthropomorphism (e.g., elicited agent knowledge, effectance motivation, and sociality motivation)

Examine how antecedents impact different types of anthropomorphism (e.g., appearance, movement, and speech)

Assess situational antecedents (e.g., customer alone or accompanied, time pressure)

Test more complex interactions among antecedents (e.g., need for interaction may change over the customer's lifetime)

Test novel individual-level moderators (e.g., proactive vs. reactive robot interaction, physical distance, and preference for personal space)

Calculate more complex individual-level moderating effects (e.g., female customers' reactions to male robots and vice versa)

Explore theoretically meaningful study-level moderators (e.g., national culture and emerging markets; Blut and Wang 2020)

Assess interesting moderators proposed in the international business literature (e.g., cross-national differences; Swoboda et al. 2016)

Test further service classifications (e.g., based on TTF theory; Goodhue and Thompson 1995)

5. Consider alternate drivers of service robot use in Examine alternate drivers for service robot use in different contexts (e.g., hedonic or functional use context; stages of the customer journey; robot quality)

Examine the role of intrinsic motivation and cognitive absorption in hedonic service robot use contexts (e.g., for entertainment in waiting areas)

Consider the impact of duration, intensity, and engagement level of robot interaction across pre-purchase, purchase, and post-purchase phases

Examine sensual perceptions in contexts where interactions with service robots are longer and more intensive

Assess emotions and feelings of ownership in contexts where interactions with service robots are longer, more frequent, more intensive, or reoccurring

Assess whether the proposed model holds for initial, as well as repeated, robot interaction (anthropomorphism may take time to display an effect on mediators such as rapport); differentiate between assimilation, diffusion, and routinization stages of technology use

Sample and study meaningful technologies (e.g., educational robots)

Employ qualitative studies to explore when negative effects of anthropomorphism are more likely (uncanny valley theory) 
this theory. Studies should assess whether these antecedents equally impact the robot's anthropomorphism in terms of its appearance, movement, and speech. Further, some antecedents may be contextually relevant only. Customers may react to robots differently when they are accompanied by someone else versus being alone with the robot. Since customers have limited experience with robots, it is likely that the importance of predictors will change over time (Venkatesh et al. 2012).

\section{Consider novel moderators and more complex moderating effects}

We tested a number of moderators related to the robot type and service context; however, several of these moderators were nonsignificant. Future studies should test novel moderators measured at the individual customer level (e.g., proactive vs. reactive robot interaction; preference for personal space), or at the study level (e.g., national culture and emerging markets). In meta-analyses it is often difficult to assess customerlevel moderators such as the need for interaction, tendency to anthropomorphize objects, and type of interaction (e.g., duration of interaction). Future research should test more complex moderating effects at the individual level (e.g., how female customers react to male robots and vice versa). At the study level, the international business literature proposes various frameworks to assess cross-national differences that may impact the effects of anthropomorphism (Swoboda et al. 2016). Most studies have been conducted in only a few countries, with a focus on the US. Scholars should thus consider additional country differences using primary data. Similarly, scholars could test other service classifications based on TTF theory, since this theory has proven useful.

\section{Consider alternate drivers of service robot use in different service contexts}

We examined the same antecedents for all service types in our model and found some significant effects; however, it may be that certain unique determinants of anthropomorphism only matter in some contexts. Future studies should therefore develop unique models for different service contexts (e.g., hedonic, emotional, and temporal services). For example, variables related to intrinsic motivation, such as control, curiosity, enjoyment, immersion, and temporal dissociation, have been shown to serve as antecedents to usefulness perceptions and behavioral intentions of hedonic information technology (Agarwal and Karahanna 2000; Lowry et al. 2012). These variables could also explain service robot usage in hedonic contexts, such as robots in waiting areas to entertain waiting customers. To further understanding, future research should consider differences in the perceptions of human-robot interaction at different stages of the customer journey and explore how encounters at different stages impact customer behavior
(Hoyer et al. 2020; Hollebeek et al. 2019). When interactions with service robots are longer and more intensive, studies should explore how customers experience robots through their senses, how this impacts their perception of the robot as product vs. a living entity, and how it affects "robot quality" perceptions. Also, it would be interesting to explore which emotions arise if customers have more intensive and more frequent interactions with the same robot. Perhaps, they will perceive a sense of ownership. Addressing this aspect and exploring the context of service robot ownership and possession could also be a fruitful research avenue.

Use different research designs Future research should use more diverse research designs. Many studies considered here were conducted in lab settings or via surveys and few measured actual customer behavior. Studies should use longitudinal designs and assess whether anthropomorphism impacts use intention differently at different stages of technology use (i.e., assimilation, diffusion, routinization). Scholars should sample customers from underresearched contexts (e.g., educational robots) to study contextual differences. We also recommend the use of more qualitative methods to identify new factors impacting anthropomorphism. We hope scholars will find this research agenda inspiring, and that more scholars engage in studying this exciting and important field.

Supplementary Information The online version contains supplementary material available at https://doi.org/10.1007/s11747-020-00762-y.

Open Access This article is licensed under a Creative Commons Attribution 4.0 International License, which permits use, sharing, adaptation, distribution and reproduction in any medium or format, as long as you give appropriate credit to the original author(s) and the source, provide a link to the Creative Commons licence, and indicate if changes were made. The images or other third party material in this article are included in the article's Creative Commons licence, unless indicated otherwise in a credit line to the material. If material is not included in the article's Creative Commons licence and your intended use is not permitted by statutory regulation or exceeds the permitted use, you will need to obtain permission directly from the copyright holder. To view a copy of this licence, visit http://creativecommons.org/licenses/by/4.0/.

\section{References}

Agarwal, R., \& Karahanna, E. (2000). Time flies when you're having fun. MIS Quarterly, 24(4), 665-694.

Aggarwal, P., \& McGill, A. L. (2012). When brands seem human, do humans act like brands? Journal of Consumer Research, 39(2), 307-323.

Albers, S., Mantrala, M. K., \& Sridhar, S. (2010). Personal selling elasticities: A meta-analysis. Journal of Marketing Research, 47(5), 840-853. 
Al-Natour, S., Benbasat, I., \& Cenfetelli, R. (2011). The adoption of online shopping assistants. Journal of the Association for Information Systems, 12(5), 347-374.

Aroyo, A. M., Rea, F., \& Sciutti, A. (2017). Will you rely on a robot to find a treasure?. In Proceedings of the Companion of the 2017 ACM/ IEEE International Conference on Human-Robot Interaction, 7172.

Athanasiou, A., Xygonakis, I., Pandria, N., Kartsidis, P., Arfaras, G., Kavazidi, K. R., Foroglou, N., Astaras, A., \& Bamidis, P. D. (2017). Towards rehabilitation robotics: Off-the-shelf BCI control of anthropomorphic robotic arms. BioMed Research International, $2017,1-17$.

Bartneck, C., Kulić, D., Croft, E., \& Zoghbi, S. (2009). Measurement instruments for the anthropomorphism, animacy, likeability, perceived intelligence, and perceived safety of robots. International Journal of Social Robotics, 1(1), 71-81.

Belanche, D., Casaló, L. V., Flavián, C., \& Schepers, J. (2020). Service robot implementation: A theoretical framework and research agenda. Service Industries Journal, 40(3-4), 203-225.

Benlian, A., Klumpe, J., \& Hinz, O. (2019). Mitigating the intrusive effects of smart home assistants by using anthropomorphic design features. Information Systems Journal, 2019, 1-33.

Bergh, D. D., Aguinis, H., Heavey, C., Ketchen, D. J., Boyd, B. K., Su, P., Lau, C. L., \& Joo, H. (2016). Using meta-analytic structural equation modeling to advance strategic management research. Strategic Management Journal, 37(3), 477-497.

Blut, M., \& Wang, C. (2020). Technology readiness: A meta-analysis of conceptualizations of the construct and its impact on technology usage. Journal of the Academy of Marketing Science, 48(4), 649669.

Blut, M., Wang, C., \& Schoefer, K. (2016). Factors influencing the acceptance of self-service technologies: A meta-analysis. Journal of Service Research, 19(4), 396-416.

Blut, M., Wünderlich, N., and Brock, C. (2018). Innovative technologies in branded-service encounters. In 39th International conference on information systems, Association for Information Systems, San Francisco, CA.

Bolton, R. N., McColl-Kennedy, J. R., Cheung, L., Gallan, A., Orsingher, C., Witell, L., \& Zaki, M. (2018). Customer experience challenges. Journal of Service Management, 29(5), 776-808.

Bosmans, A. (2006). Scents and sensibility: When do (in) congruent ambient scents influence product evaluations? Journal of Marketing, 70(3), 32-43

Broadbent, E., Stafford, R., \& MacDonald, B. (2009). Acceptance of healthcare robots for the older population: Review and future directions. International Journal of Social Robotics, 1(4), 319-330.

Broadbent, E., Jayawardena, C., Kerse, N., Stafford, R.Q., and MacDonald, B.A. (2011). Human-robot interaction research to improve quality of life in elder care: An approach and issues. In 25th conference on artificial intelligence. AAAI Workshop, San Francisco, CA.

Burgoon, J. K., Bonito, J. A., Bengtsson, B., Cederberg, C., Lundeberg, M., \& Allspach, L. (2000). Interactivity in human-computer interaction. Computers in Human Behavior, 16(6), 553-574.

Canning, C., Donahue, T.J., and Scheutz, M. (2014). Investigating human perceptions of robot capabilities in remote human-robot team tasks based on first-person robot video feeds. In Proceedings of intelligent robots and systems, L. Kevin and P. Lynne (eds.), Chicago, IL: Institute of Electrical and Electronics Engineers (IEEE), Curran Associates, Inc, 4354-4461.

Carpenter, J., Davis, J. M., Erwin-Stewart, N., Lee, T. R., Bransford, J. D., \& Vye, N. (2009). Gender representation and humanoid robots designed for domestic use. International Journal of Social Robotics, 1(3), 261-265.

Castro-González, A., Alcocer-Luna, J., Malfaz, M., Alonso-Martín, F., \& Salichs, M. A. (2018). Evaluation of artificial mouths in social robots. IEEE Transactions on Human-Machine Systems, 48(4), 369-379.

Chan, A. P. H., \& Tung, V. W. S. (2019). Examining the effects of robotic service on brand experience. Journal of Travel and Tourism Marketing, 36(4), 458-468.

Coghlan, S., Waycott J., Neve, B.B., Vetere, F. (2018). Using robot pets instead of companion animals for older people. In 30th Australian conference on computer-human interaction, 172-183.

Dabholkar, P. A. (1996). Consumer evaluations of new technology-based self-service options. International Journal of Research in Marketing, 13(1), 29-51.

Davis, F. D., Bagozzi, R. P., \& Warshaw, P. R. (1989). User acceptance of computer technology: A comparison of two theoretical models. Management Science, 35(8), 982-1003.

De Visser, E. J., Monfort, S. S., McKendrick, R., Smith, M. A., McKnight, P. E., Krueger, F., \& Parasuraman, R. (2016). Almost human: Anthropomorphism increases trust resilience in cognitive agents. Journal of Experimental Psychology: Applied, 22(3), 331349.

Destephe, M., Brandao, M., Kishi, T., Zecca, M., Hashimoto, K., \& Takanishi, A. (2015). Walking in the uncanny valley. Frontiers in Psychology, 6, 1-11.

van Doorn, J., Mende, M., Noble, S. M., Hulland, J., Ostrom, A. L., Grewal, D., \& Petersen, J. A. (2017). Domo arigato Mr. Roboto: Emergence of automated social presence in organizational frontlines and customers' service experiences. Journal of Service Research, 20(1), 43-58.

Duffy, B. R. (2003). Anthropomorphism and the social robot. Robotics and Autonomous Systems, 42(3-4), 177-190.

Epley, N., Waytz, A., \& Cacioppo, J. T. (2007). On seeing human: A three-factor theory of anthropomorphism. Psychological Review, 114(4), 864-886.

Epley, N., Waytz, A., Akalis, S., \& Cacioppo, J. T. (2008). When we need a human: Motivational determinants of anthropomorphism. Social Cognition, 26(2), 143-155.

Erebak, S., \& Turgut, T. (2019). Caregivers' attitudes toward potential robot coworkers in elder care. Cognition, Technology and Work, 21, 327-336.

Eyssel, F., \& Hegel, F. (2012). (S)he's got the look: Gender stereotyping of robots. Journal of Applied Social Psychology, 42(9), 2213-2230.

Fan, A., Wu, L. L., \& Mattila, A. S. (2016). Does anthropomorphism influence customers' switching intentions in the self-service technology failure context? Journal of Services Marketing, 30(7), 713723.

Ferrari, F., Paladino, M. P., \& Jetten, J. (2016). Blurring human-machine distinctions. International Journal of Social Robotics, 8(2), 287 302.

Fink, J. (2012). Anthropomorphism and human likeness in the design of robots and human-robot interaction. In Ge S.S., Khatib O., Cabibihan J.J., Simmons R., Williams M.A. (eds.) Social Robotics. ICSR 2012. Lecture Notes in Computer Science. Springer, Berlin, Heidelberg, 199-208.

Fishbach, A., \& Labroo, A. A. (2007). Be better or be merry: How mood affects self-control. Journal of Personality and Social Psychology, 93(2), 158-173.

Fong, T., Nourbakhsh, I., \& Dautenhahn, K. (2003). A survey of socially interactive robots. Robotics and Autonomous Systems, 42(3-4), 143-166.

Friedman, B., Kahn Jr., P.H., and Hagman, J. (2003). Hardware companions? What online AIBO discussion forums reveal about the humanrobotic relationship. In SIGCHI conference, Association for Computing Machinery, New York, NY, 273-280.

Fussell, S.R., Kiesler, S., Setlock, L.D., and Yew, V. (2008). How people anthropomorphize robots. In $3 r d$ ACM/IEEE International conference on human-robot interaction, Association for Computing Machinery, New York, NY, 145-152. 
Gnambs, T., \& Appel, M. (2019). Are robots becoming unpopular? Changes in attitudes towards autonomous robotic systems in Europe. Computers in Human Behavior, 93, 53-61.

Goetz, J., Kiesler, S., and Powers, A. (2003). Matching robot appearance and behavior to tasks to improve human-robot cooperation. In 12 th IEEE International workshop on robot and human interactive communication, IEEE, Millbrae, CA, 55-60.

Goodhue, D. L., \& Thompson, R. L. (1995). Task-technology fit and individual performance. MIS Quarterly, 19(2), 213-236.

Goudey, A., \& Bonnin, G. (2016). Must smart objects look human? Recherche et Applications en Marketing, 31(2), 2-20.

de Graaf, M. M., \& Allouch, S. B. (2013). Exploring influencing variables for the acceptance of social robots. Robotics and Autonomous Systems, 61(12), 1476-1486.

Grewal, D., Puccinelli, N., \& Monroe, K. B. (2018). Meta-analysis: Integrating accumulated knowledge. Journal of the Academy of Marketing Science, 46(1), 9-30.

Ham, J., Cuijpers, R. H., \& Cabibihan, J. J. (2015). Combining robotic persuasive strategies: The persuasive power of a storytelling robot that uses gazing and gestures. International Journal of Social Robotics, 7(4), 479-487.

Hancock, P. A., Billings, D. R., Schaefer, K. E., Chen, J. Y. C., de Visser, E. J., \& Parasuraman, R. (2011). A meta-analysis of factors affecting trust in human-robot interaction. Human Factors, 53(5), 517-527.

Haring, K.S., Watanabe, K., Silvera-Tawil, D., Velonaki, M., and Takahashi, T. (2015). Changes in perception of a small humanoid robot. In 2015 6th International conference on automation, robotics and applications, 83-89.

Haring, K. S., Silvera-Tawil, D., Takahashi, T., Watanabe, K., \& Velonaki, M. (2016). How people perceive different robot types: A direct comparison of an android, humanoid, and nonbiomimetic robot. In 2016 8th International Conference on Knowledge and Smart Technology (KST). IEEE 265-270

Heerink, M., Kröse, B., Evers, V., \& Wielinga, B. (2008). The influence of social presence on acceptance of a companion robot by older people. Journal of Physical Agents, 2(2), 33-34.

Ho, C. C., \& MacDorman, K. F. (2010). Revisiting the uncanny valley theory. Computers in Human Behavior, 26(6), 1508-1518.

Hollebeek, L. D., Sprott, D. E., Andreassen, T. W., Costley, C., Klaus, P., Kuppelwieser, V., Karahasanovic, A., Taguchi, T., Ul Islam, J., \& Rather, R. A. (2019). Customer engagement in evolving technological environments: Synopsis and guiding propositions. European Journal of Marketing, 53(9), 2018-2023.

Hoyer, W. D., Kroschke, M., Schmitt, B., Kraume, K., \& Shankar, V. (2020). Transforming the customer experience through new technologies. Journal of Interactive Marketing, 51, 57-71. https://doi.org/ 10.1016/j.intmar.2020.04.001.

Huang, M. H., \& Rust, R. T. (2017). Technology-driven service strategy. Journal of the Academy of Marketing Science, 45(6), 906-924.

Huang, M. H., \& Rust, R. T. (2018). Artificial intelligence in service. Journal of Service Research, 21(2), 155-172.

Huang, M. H., \& Rust, R. T. (2020). Engaged to a robot? The role of AI in service. Journal of Service Research. https://doi.org/10.1177/ 1094670520902266

Hunter, J. E., \& Schmidt, F. L. (2004). Methods of meta-analysis (2nd ed.). Thousand Oaks, CA: Sage.

Hur, J. D., Koo, M., \& Hofmann, W. (2015). When temptations come alive: How anthropomorphism undermines self-control. Journal of Consumer Research, 42(2), 340-358.

Iacobucci, D., Ostrom, A., \& Grayson, K. (1995). Distinguishing service quality and customer satisfaction: the voice of the consumer. Journal of Consumer Psychology, 4(3), 277-303.

Iyer, G. R., Blut, M., Xiao, S. H., \& Grewal, D. (2020). Impulse buying: A meta-analytic review. Journal of the Academy of Marketing Science, 48(3), 384-404.
Joerling, M., Böhm, R., \& Paluch, S. (2019). Service robots: Drivers of perceived responsibility for service outcomes. Journal of Service Research, 22(4), 404-420.

Kamide, H., Kawabe, K., Shigemi, S., \& Arai, T. (2013). Development of a psychological scale for general impressions of humanoid. Advanced Robotics, 27(1), 3-17.

Kätsyri, J., Förger, K., Mäkäräinen, M., \& Takala, T. (2015). A review of empirical evidence on different uncanny valley hypotheses. Frontiers in Psychology, 6, 1-16.

Kim, S., \& McGill, A. L. (2011). Gaming with Mr. Slot or gaming the slot machine? Power, anthropomorphism, and risk perception. Journal of Consumer Research, 38(1), 94-107.

Kim, K. J., Park, E., \& Sundar, S. S. (2013). Caregiving role in humanrobot interaction. Computers in Human Behavior, 29(4), 1799 1806.

Kim, A., Cho, M., Ahn, J., \& Sung, Y. (2019). Effects of gender and relationship type on the response to artificial intelligence. Cyberpsychology, Behavior and Social Networking, 22(4), 249253.

Kleine, S. S., \& Baker, S. M. (2004). An integrative review of material possession attachment. Academy of Marketing Science Review, 1(1), $1-39$.

Knowledge Sourcing Intelligence (2018). Social robot market: Forecasts from 2018 to 2023. Accessed May 23, 2020 from https://www. researchandmarkets.com.

Kompatsiari, K., Ciardo, F., Tikhanoff, V., Metta, G., \& Wykowska, A. (2019). It's in the eyes: the engaging role of eye contact in HRI. International Journal of Social Robotics, 1-11.

Kuo, I.H. et al. (2009). Age and gender factors in user acceptance of healthcare robots. The 18th IEEE International symposium on robot and human interactive communication Toyama, IEEE, Japan, Toyama, 2009, 214-219.

Lastovicka, J. L., \& Sirianni, N. J. (2011). Truly, madly, deeply: Consumers in the throes of material possession love. Journal of Consumer Research, 38(2), 323-342.

Leng, M., Liu, P., Zhang, P., Hu, M., Zhou, H., Li, G., Yin, H., \& Chen, L. (2019). Pet robot intervention for people with dementia. Psychiatry Research, 271, 516-525.

Leong, B., and Selinger, E. (2019). Robot eyes wide shut: Understanding dishonest anthropomorphism. In Proceedings of the conference on fairness, accountability, and transparency, Association for Computing Machinery, Atlanta, GA, 299-308.

Li, D., Rau, P. P., \& Li, Y. (2010). A cross-cultural study: Effect of robot appearance and task. International Journal of Social Robotics, 2(2), $175-186$

Lowry, P. B., Gaskin, J., Twyman, N., Hammer, B., \& Roberts, T. (2012). Taking "fun and games" seriously. Journal of the Association for Information Systems, 14(11), 617-671.

Lussier, D. A., \& Olshavsky, R. W. (1979). Task complexity and contingent processing in brand choice. Journal of Consumer Research, 6(2), 154-165.

MacDorman, K. F., Vasudevan, S. K., \& Ho, C. C. (2009). Does Japan really have robot mania? Comparing attitudes by implicit and explicit measures. AI and Society, 23(4), 485-510.

MacInnis, D. J., \& Folkes, V. S. (2017). Humanizing brands: When brands seem to be like me, part of me, and in a relationship with me. Journal of Consumer Psychology, 27(3), 355-374.

Mazodier, M., Henderson, C. M., \& Beck, J. T. (2018). The long reach of sponsorship. Journal of Marketing, 82(6), 28-48.

Melson, G. F., Kahn Jr., P. H., Beck, A., \& Friedman, B. (2009). Robotic pets in human lives. Journal of Social Issues, 65(3), 545-567.

Mende, M., Scott, M. L., van Doorn, J., Grewal, D., \& Shanks, I. (2019). Service robots rising: How humanoid robots influence service experiences and elicit compensatory consumer responses. Journal of Marketing Research, 56(4), 535-556.

Mori, M. (1970). The uncanny valley. Energy, 7(4), 33-35. 
Moshkina, L. V. (2011). An integrative framework of time-varying affective robotic behavior, Doctoral dissertation, Georgia Institute of Technology.

Munro, M. C., Huff, S. L., Marcolin, B. L., \& Compeau, D. R. (1997). Understanding and measuring user competence. Information and Management, 33(1), 45-57.

Nass, C., \& Moon, Y. (2000). Machines and mindlessness: Social responses to computers. Journal of Social Issues, 56(1), 81-103.

Nenkov, G. Y., \& Scott, M. L. (2014). "So cute I could eat it up": Priming effects of cute products on indulgent consumption. Journal of Consumer Research, 41(2), 326-341.

Niemelä, M., Heikkilä, P., and Lammi, H. (2017). A social service robot in a shopping mall: Expectations of the management, retailers and consumers. In HRI '17: ACM/IEEE International conference on human-robot interaction, Association for Computing Machinery, New York, NY.

Nittono, H., \& Ihara, N. (2017). Psychophysiological responses to kawaii pictures with or without baby schema. SAGE Open, 7(2), 1-11.

Nomura, T. (2017). Robots and gender. Gender and the Genome, 1(1), $18-25$.

Nomura, T., Kanda, T., \& Suzuki, T. (2006). Experimental investigation into influence of negative attitudes toward robots on human-robot interaction. AI and Society, 20(2), 138-115.

Norouzi-Gheidari, N., Archambault, P. S., \& Fung, J. (2012). Effects of robot-assisted therapy on stroke rehabilitation in upper limbs. Journal of Rehabilitation Research and Development, 49(4), 479495.

Novak, T. P., \& Hoffman, D. L. (2019). Relationship journeys in the internet of things: A new framework for understanding interactions between consumers and smart objects. Journal of the Academy of Marketing Science, 47(2), 216-237.

Novikova, J. (2016). Designing emotionally expressive behaviour: Intelligibility and predictability in human-robot interaction, doctoral dissertation, University of Bath.

Ooi, K. B., \& Tan, G. W. H. (2016). Mobile technology acceptance model: An investigation using mobile users to explore smartphone credit card. Expert Systems with Applications, 59, 33-46.

Orsingher, C., Valentini, S., \& de Angelis, M. (2009). A meta-analysis of satisfaction with complaint handling in services. Journal of the Academy of Marketing Science, 38(2), 169-186.

Otto, A. S., Szymanski, D. M., \& Varadarajan, R. (2020). Customer satisfaction and firm performance. Journal of the Academy of Marketing Science, 48(3), 543-564.

Peck, J., \& Childers, T. L. (2006). If I touch it I have to have it: Individual and environmental influences on impulse purchasing. Journal of Business Research, 59(6), 765-769.

Pfeifer, R., Lungarella, M., \& Iida, F. (2007). Self-organization, embodiment, and biologically inspired robotics. Science, 318(5853), 10881093.

van Pinxteren, M. M. E., Ruud, W. H., Wetzels, J. R., Pluymaekers, M., \& Wetzels, M. (2019). Trust in humanoid robots. Journal of Services Marketing, 33(4), 507-518.

Powers, A., and Kiesler, S. (2006). The advisor robot: Tracing people's mental model from a robot's physical attributes. Conference on human-robot interaction (HRI 2006), Association for Computing Machinery, Salt Lake City, UT, 218-225.

$\mathrm{Pu}$, L., Moyle, W., Jones, C., \& Todorovic, M. (2019). The effectiveness of social robots for older adults. The Gerontologist, 59(1), e37-e51.

Qiu, L., \& Benbasat, I. (2009). Evaluating anthropomorphic product recommendation agents. Journal of Management Information Systems, 25(4), 145-182.

Qiu, H., Li, M., Shu, B., \& Bai, B. (2020). Enhancing hospitality experience with service robots. Journal of Hospitality Marketing and Management, 29(3), 247-268.

Rae, I., Takayama, L., and Mutlu, B. (2013). In-body experiences: Embodiment, control, and trust in robot-mediated communication.
In SIGCHI conference, Association for Computing Machinery, 1921-1930.

Rosenthal, R. (1979). The file drawer problem and tolerance for null results. Psychological Bulletin, 86(3), 638-641.

Ruijten, P., and Cuijpers, R. (2017). Dynamic perceptions of humanlikeness while interacting with a social robot. In 2017 ACM/IEEE International conference on human-robot interaction, 273-274.

Schneider, S., Häßler, A., Habermeyer, T., Beege, M., \& Rey, G. D. (2019). The more human, the higher the performance? Journal of Educational Psychology, 111(1), 57-72.

Salem, M., Eyssel, F., Rohlfing, K., Kopp, S., \& Joublin, F. (2013). To err is human (-like): Effects of robot gesture on perceived anthropomorphism and likability. International Journal of Social Robotics, 5(3), 313-323.

Sharkey, N., \& Sharkey, A. (2011). The rights and wrongs of robot care. In Lin et al. (Eds.), Robot ethics: The ethical and social implications of robotics (pp. 267-282). Cambridge: MIT Press.

Sherman, G. D., Haidt, J., \& Coan, J. A. (2009). Viewing cute images increases behavioral carefulness. Emotion, 9(2), 282-286.

Spence, J. T., Helmreich, R. L., \& Stapp, J. (1974). The personal attributes questionnaire: A measure of sex role stereotypes and masculinity-femininity. Journal Supplement Abstract Service, 4, 1-42.

Stafford, R. (2014). The contribution of people's attitudes and perceptions to the acceptance of eldercare robots. Doctoral dissertation, ResearchSpace@ Auckland.

Stroessner, S. J., \& Benitez, J. (2019). The social perception of humanoid and non-humanoid robots. International Journal of Social Robotics, 11(2), 305-315.

Swoboda, B., Puchert, C., \& Morschett, D. (2016). Explaining the differing effects of corporate reputation across nations. Journal of the Academy of Marketing Science, 44(4), 454-473.

Thomaz, F., Salge, C., Karahanna, E., \& Hulland, J. (2020). Learning from the dark web: Leveraging conversational agents in the era of hyper-privacy to enhance marketing. Journal of the Academy of Marketing Science, 48(1), 43-63.

Veerbeek, J. M., Langbroek-Amersfoort, A. C., Van Wegen, E. E., Meskers, C. G., \& Kwakkel, G. (2017). Effects of robot-assisted therapy for the upper limb after stroke: A systematic review and meta-analysis. Neurorehabilitation and Neural Repair, 31(2), $107-121$.

Venkatesh, V. (2000). Determinants of perceived ease of use. Information Systems Research, 11(4), 342-365.

Venkatesh, V., Thong, J. Y., \& Xu, X. (2012). Consumer acceptance and use of information technology: Extending the unified theory of acceptance and use of technology. MIS Quarterly, 36(1), 157-178.

Vlachos, E., Jochum, E., \& Demers, L. P. (2016). The effects of exposure to different social robots on attitudes toward preferences. Interaction Studies, 17(3), 390-404.

Wainer, J., Feil-Seifer, D.J., Shell, D.A., and Mataric, M.J. (2006). The role of physical embodiment in human-robot interaction. In IEEE International symposium, IEEE, 117-122.

Waytz, A., Heafner, J., \& Epley, N. (2014). The mind in the machine: Anthropomorphism increases trust in an autonomous vehicle. Journal of Experimental Social Psychology, 52, 113-117.

Westbrook, R. A. (1987). Product/consumption-based affective responses and postpurchase processes. Journal of Marketing Research, 24, 258-270.

Wirtz, J., and Lovelock, C. (2016). Services marketing: People, technology, strategy. Hackensack, NJ: World Scientific Publishing Company.

Wirtz, J., Patterson, P. G., Kunz, W. H., Gruber, T., Lu, V. N., Paluch, S., $\&$ Martins, A. (2018). Brave new world: Service robots in the frontline. Journal of Service Management, 29(50), 907-931.

Wünderlich, N.V., and Paluch, S. (2017). A nice and friendly chat with a bot. 38th International conference on information systems, Association for Information Systems, 1-11. 
Yu, Z., Huang, Q., Ma, G., Chen, X., Zhang, W., Li, J., \& Gao, J. (2014). Design and development of the humanoid robot BHR-5. Advances in Mechanical Engineering, 6, 852937.

Zhang, T., Kaber, DB., Zhu, B., Swangnetr, M., Mosaly, P., Hodge, L. (2010). Service robot feature design effects on user perceptions and emotional responses. Intelligent Service Robotics, 3 (2), 73-88.
Zlotowski, J., Proudfoot, D., Yogeeswaran, K., \& Bartneck, C. (2015). Opportunities and challenges in human-robot interaction. International Journal of Social Robotics, 7(3), 347-360.

Publisher's note Springer Nature remains neutral with regard to jurisdictional claims in published maps and institutional affiliations. 